\begin{tabular}{|l|l|l|l|l|l|}
\hline MUNIBE Antropologia-Arkeologia & $\mathrm{n}^{\circ} 72$ & $25-42$ & DONOSTIA & 2021 & ISSN 1132-2217 • eISSN 2172-4555 \\
\hline
\end{tabular}

\title{
El uso de materias colorantes en el Paleolítico superior de la cueva de Lumentxa (Lekeitio, Bizkaia, Norte de la Península Ibérica)
}

\section{The use of colouring materials during the Upper Palaeolithic period in the Lumentxa cave (Lekeitio, Biscay, Northern Iberian Peninsula)}

PALABRAS CLAVES: Magdaleniense, Pigmentos, Huellas de uso, Crayón, Golfo de Bizkaia GAKO-HITZAK: Madeleine aldia, Pigmentuak, Erabileraren arrastoak, Arkatza, Bizkaiko Golkoa. KEY WORDS: Magdalenian, Pigments, Traces of use, Crayon, Bay of Biscay.

\section{José Luis ARRIBAS PASTOR ${ }^{(1)}$, Eduardo BERGANZA GOCHI(2), Jon Mirena BETANZOS TROJAOLA ${ }^{(3)}$}

\section{RESUMEN}

El ocre es un material colorante utilizado desde épocas antiguas por los cazadores-recolectores de todo el planeta. Estudiamos 34 objetos recuperados en los niveles magdalenienses de la cueva de Lumentxa durante las intervenciones de los años veinte del siglo pasado. En 14 ejemplares hemos reconocido huellas de modificación antropogénica. Las características de las huellas indican que éstas se produjeron por un desgaste ocasionado por tres acciones diferentes: la molienda sobre superficies abrasivas, el rayado con instrumentos afilados y el frotado de materias blandas. Molienda y rayado son procedimientos para la obtención de polvo de ocre destinado a actividades domésticas o simbólicas. Las marcas de frotado evidencian, entre otros usos, la aplicación directa del colorante con finalidades funcionales u ornamentales.

\section{LABURPENA}

Okrea, ehiztari-biltzaileak planeta osoan aintzinatik erabilitako gai koloragarria da. Lumentxako haitzuloan, XX. mendearen 20ko hamarkadako esku-hartzean aurkitutako Madalen aldiko 34 objektu ikertu ditugu. 14 aletan eragin antropogenoak nabaritzen dira; hiru motatako higadurak, hain zuzen. Bata, azal urratzailearen gaineko ehotzeagatik; bestea, tresna zorrotzekin egindako marraduragatik, eta, hirugarrena, gai bigunekin igurtzearen ondoriozkoa. Ehotzeaz eta marraduraz baliatzen ziren okre hautsak lortzeko, eta horiek etxeko lanetan edo ekintza sinbolikoetan erabiltzen ziren. Igurtzea, besteak beste, koloragarria bertan jartzeko.

\section{ABSTRACT}

Ochre is a colouring material used since ancient times by hunter-gatherers all over the planet. We studied the collection of 34 artefacts retrieved from the Magdalenian levels of the Lumentxa cave during the interventions carried out in the 1920's. Slightly more than $50 \%$ are siderite - lutite nodules or fragments of such nodules, which may have been collected from Cretaceous outcrops near the settlement. The rest are soft, reddish materials with an earthy-clayey mould. By means of macroscopic and microscopic observation, we have identified traces of anthropogenic modification on 14 specimens.

The characteristics of the traces indicate that they were produced by surface wear and tear caused by three different actions: grinding on abrasive surfaces, scratching with sharp instruments, and the rubbing of soft materials. The most common traces are those caused by rubbing. They have been identified as the only trace in nine specimens and in another two cases they have been found in association with other traces. Grinding was the activity that generated the modelling of the two pieces defined as crayon. The incisions and grooves that can be seen on three slab pieces were caused by scratching. Grinding and scratching are processes used to obtain fine ochre powder for different domestic or symbolic activities. The traces of rubbing bear witness to the direct application of the dye.

We may associate the use of dyes in the Lumentxa cave with a wide range of domestic and symbolic activities. It is clearly linked to graphic expression. This can be seen in the choice of a slab that had served as a natural block on which to obtain ochre powder as a support material for the representation of engraved horse figures or in the use of red pigments for the pictorial representations on the walls of the cavity. In the light of similar replicative experiences, we can assume that it was used in leather work, in the composition of adhesive mixtures for attaching lithic artefacts to hafts, in body painting or on other surfaces.

\footnotetext{
(1) AOZTA. arribas.pastor@gmail.com. Alameda de Rekalde, 63-3ํ․ 48012 BILBAO.

(2) AOZTA. eduberganza@gmail.com.

(3) Departamento de Estratigrafía y Paleontología, UPV/EHU
} 


\section{INTRODUCCIÓN}

La captación, procesado y uso de materias colorantes fue una práctica extendida en las comunidades de cazadores-recolectores, al menos desde el Pleistoceno Medio. Así lo atestiguan los restos recuperados en numerosos asentamientos de la Edad de la Piedra Media en el África austral y oriental (MSA) (d'Errico et al., 2003; Watts, 2010; Rosso, 2017a; Rosso et al., 2017a; Hodgskiss, 2013 y 2020), al igual que en otros localizados en diferentes regiones del continente euroasiático con conjuntos tecnoindustriales propios del Paleolítico inferior y medio (Zilhão et al., 2010; d'Errico et al., 2010; Roebroeks et al, 2012; Salomon et al., 2012; Peresani et al., 2013; Sinddall, 2018). La expansión de los grupos de humanos modernos intensificó su explotación y las evidencias de procesado de ocre se incrementan en los registros de niveles con industrias del Paleolítico superior (Audouin y Plisson, 1982; Groenen, 1991; Salomon, 2009; Pradeau et al., 2014; Normand, 2017; Velliky et al., 2018; Aura Tortosa et al., 2020). En las últimas décadas están siendo objeto de estudios orientados a analizar los procesos técnicos o cadenas operativas desarrollados para su captación y transformación y a determinar los usos a que fueron destinados (d`Errico, 2003; Henshilwood et al., 2009; García Díez et al., 2009; Cortell, 2016; Rosso, 2017b).

En el ámbito geográfico de la cornisa cantábrica y del Pirineo occidental es escasa la atención prestada al registro de vestigios colorantes recuperados en niveles del Paleolítico superior, más allá de los soportes utilizados para representaciones de arte mobiliar o de adorno personal (Aranzadi y Barandiaran, 1934; González Echegaray et al, 1963; San Juan, 1983; Utrilla, 1982; Rodríguez y Barrera, 2015). Estudios sistemáticos de estos materiales se han realizado en fechas recientes para los conjuntos hallados en las cuevas de La Garma (Omoño, Ribamontán al Monte) (Arias et al., 2011), El Mirón (Ramales de la Victoria, Cantabria) (Seva Román et al., 2015 y 2019), Coímbre (Peñamellera Alta, Asturias) (García Madariaga et al., 2017), Praileaitz I (Deba, Gipuzkoa) (Queffelec et al., 2017), Isturitz (Saint-Martin-d'Arberoue, Pyrénées-Atlantiques) (Normand, 2017) y Zatoya (Abaurrea Alta, Navarra) (Laborda Martínez, 2018).

En la revisión de los materiales procedentes de las excavaciones históricas (1926-1929) del yacimiento de Lumentxa (Lekeitio, Bizkaia), que se conservan en el Arkeologi Museoa de Bilbao, hemos identificado 34 objetos de considerables dimenciones que podrían denominarse, en sentido genérico, ocres arqueológicos (Watts, 2009; Hodgskiss, 2010 y 2013). La colección ha sido analizada con un enfoque descriptivo e interpretativo tomando como referencia los modelos desarrollados en las últimas décadas para el estudio de los pigmentos y substancias colorantes encontrados en asentamientos del Pleistoceno medio y superior (Hodgskiss, 2013 y 2020; Rifkin, 2011 y 2012; Sinddall,
2018; Velliky et al., 2018). No hemos abordado ni análisis físico-químicos de las materias minerales, ni programas experimentales, aspectos que posponemos para otra fase del proyecto de revisión.

\section{CONTEXTO ARQUEOLÓGICO}

La cueva de Lumentxa se abre a media ladera en una colina de algo más de cien metros de altitud localizada en la zona oriental del territorio de Bizkaia, sobre la actual desembocadura del río Lea (Figura 1). La boca principal, orientada al SW, da acceso a una espaciosa sala en la que se encuentra un yacimiento arqueológico investigado desde hace un siglo.

Los primeros trabajos los llevaron a cabo T. de Aranzadi y J.M. de Barandiarán en una extensa área de la sala durante la segunda mitad de la década de los años veinte del siglo pasado. A partir de los restos arqueológicos recuperados, establecieron una secuencia de ocupaciones que abarca desde el Postneolítico hasta el Magdaleniense. El abundante y variado registro de materiales incluye artefactos industriales líticos y óseos, evidencias antropológicas, arqueozoológicas y arqueobotánicas (Aranzadi, 1929; Aranzadi y Barandiarán, 1935). Las posteriores intervenciones se produjeron en la década de los años sesenta (Barandiarán, 1965 y 1966) y a finales de la centuria. Ambas afectaron a una zona en la que sólo se conservan vestigios de ocupaciones de la Prehistoria reciente (Arribas y Berganza, 2018) (Figura 2). En fechas más recientes se localizó un conjunto pictórico de arte rupestre en el interior de la galería principal (Gárate et al., 2013).

La excavación arqueológica más reciente forma parte de un proyecto de investigación que comprende el estudio de otros dos yacimientos en cueva localizados en la cuenca baja del río Lea (Laminak II y Santa Catalina) (Berganza y Arribas, 1994; Arribas, 2004; Berganza et al., 2012a; Berganza y Arribas, 2014). El enfoque metodológico aborda, junto con el estudio interdisciplinar de los hallazgos recientes, la revisión e integración de la colección arqueológica procedente de las anteriores intervenciones (Arribas, 1997; Berganza et al., 2012b; Roselló et al., 2017 y 2018; García-Sagastibelza et al., 2020).

En las campañas de 1926 a 1929 se recuperó un conjunto de materiales colorantes catalogados como "ocre rojo", en algunos de los cuales se reconocieron "planos de desgaste", "raspaduras de uso" y "alguna raya". Los hallazgos "se acumulan entre los 0,95 y los 1,35 m de profundidad" por debajo del punto de referencia (Aranzadi y Barandiarán, 1935).

En la tabla $n^{\circ} 1$ se presenta la contextualización arqueológica de los objetos atendiendo a la profundidad asignada en la sigla, la correspondencia de la misma con los niveles arqueológicos de la secuencia establecida por los excavadores y la atribución cultural de estos. La pieza localizada a $-70 \mathrm{~cm}$ procede de un 


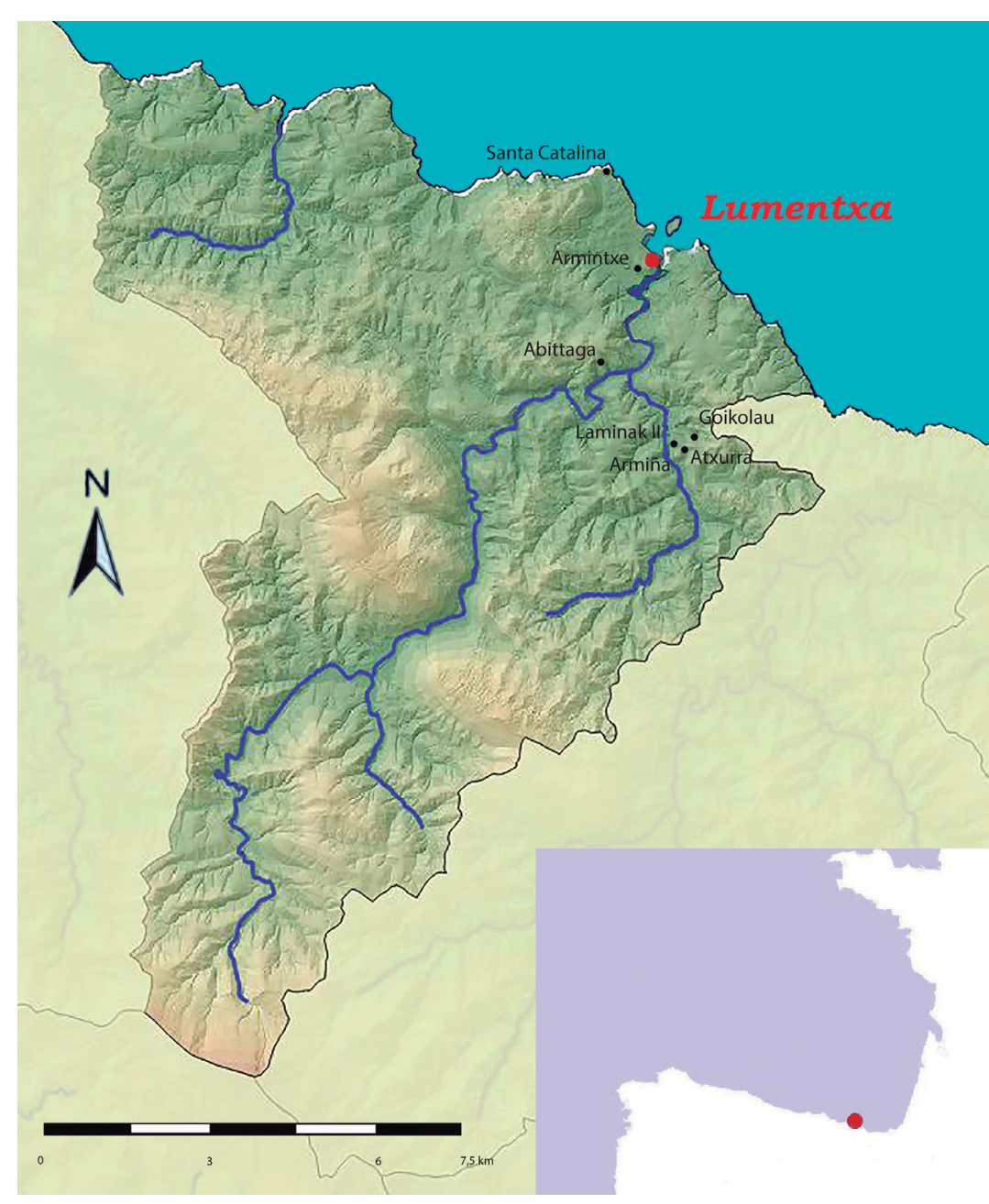

Fig.1. Localización de la cueva de Lumentxa y otros yacimientos situados en la cuenca del río Lea. / Location of the Lumentxa cave and other sites located in the Lea River basin.

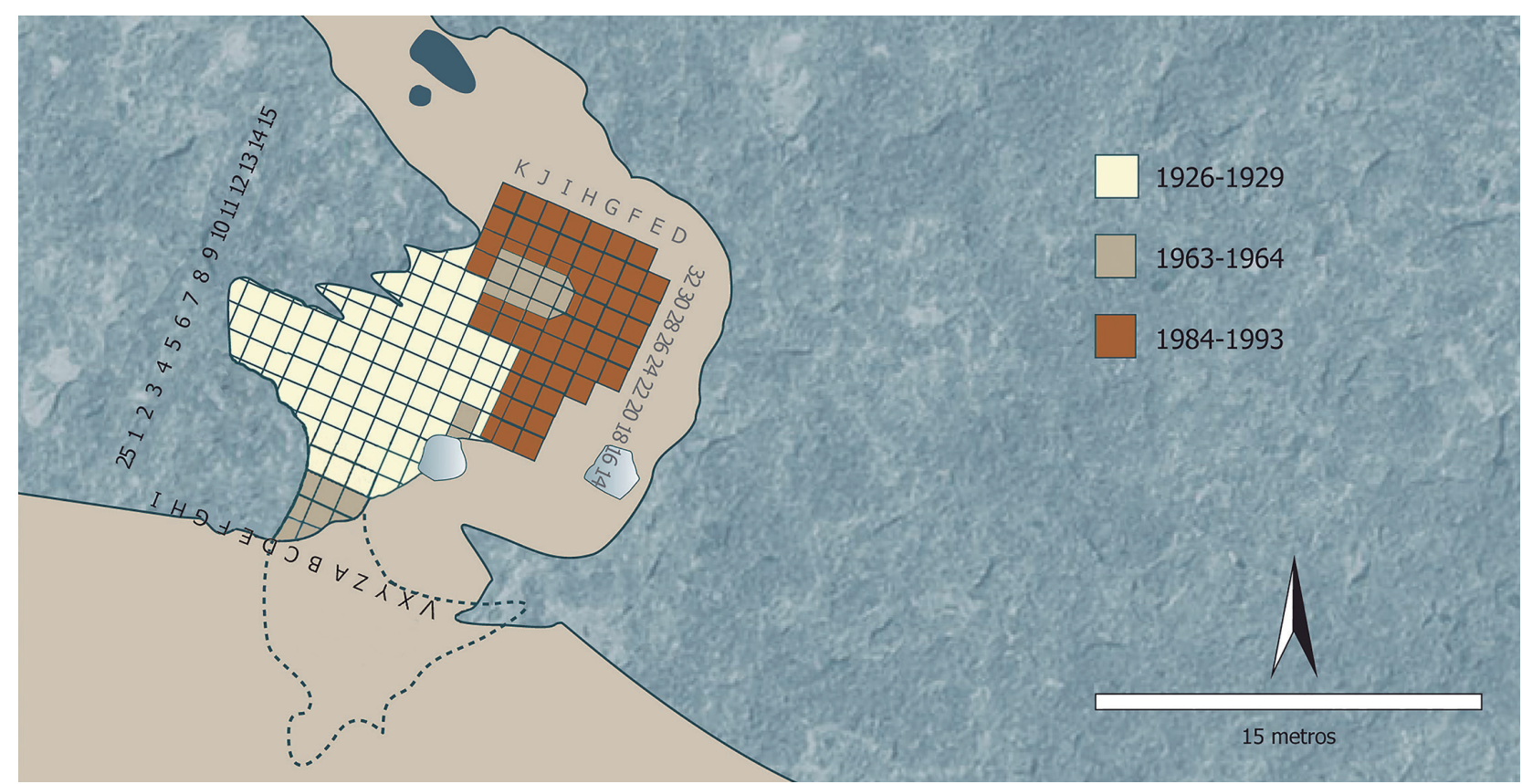

Fig.2. Planta de la sala principal con indicación de las áreas excavadas (Reelaborado a partir de Garate, 2012). / Layout of the main room showing the excavated areas (Reworked based on Garate, 2012). 
contexto estratigráfico poco preciso (nivel B o C). Los extraídos entre -90 y -145 cm se sitúan en una posición correspondiente a los estratos $\mathrm{C}$ y $\mathrm{D}$, niveles que fueron considerados magdalenienses y, posteriormente, atribuidos al Magdaleniense final y superior, respectivamente (Barandiarán, 1967; González Sainz, 1989). Los que fueron extraídos a mayor profundidad corresponden a los niveles E y F, adscritos al Magdaleniense inferior (Utrilla, 1981).

\begin{tabular}{|cccc|}
\hline Profundidad & Nivel & Atribución cultural & Objetos colorantes \\
\hline $70 \mathrm{~cm}$ & B-C & Neolítico/Aziliense & 1 \\
$90 \mathrm{~cm}$ & C & Magdaleniense final & 1 \\
$95 \mathrm{~cm}$ & C & Magdaleniense final & 3 \\
$110 \mathrm{~cm}$ & C & Magdaleniense final & 8 \\
$120 \mathrm{~cm}$ & C & Magdaleniense final & 2 \\
$145 \mathrm{~cm}$ & D & Magdaleniense superior & 15 \\
$170 \mathrm{~cm}$ & E & Magdaleniense inferior & 3 \\
$230 \mathrm{~cm}$ & F & Magdaleniense inferior & 1 \\
& & & $\mathbf{3 4}$ \\
\hline
\end{tabular}

Tabla 1: Contexto estratigráfico de los objetos de material colorante. / Stratigraphic context of the colouring material artefacts.

\section{METODOLOGÍA DE ESTUDIO}

El estado de conservación no es óptimo. La mayoría están afectados por adherencias calcáreas y arcillosas, que dificultan su observación; algunos tienen pequeñas saltaduras y fracturas modernas. El Laboratorio de Restauración del Arkeologi Museoa ha diagnosticado que el uso de tratamientos mecánicos alteraría su integridad, por lo que se ha procedido a una actuación conservadora, que no ha permitido restituir su estado original.

Todas las piezas han sido documentadas mediante observación ocular. Se ha identificado el litotipo, las propiedades físicas, definido la morfología y obtenido las dimensiones (longitud, anchura, espesor, en mm; y peso en gramos). No se han realizado análisis intrusivos de dureza y color para evitar dañarlas.

Se han localizado las zonas en las que se conservan trazas funcionales, describiendo las características cualitativas de las mismas. Para ello, se ha procedido a una observación macro y microscópica. Esta última se ha efectuado con una lupa binocular Olympus SZX10, (escala de aumentos de entre 0,63X y 6,3X), equipada con una cámara digital Olympus DP 25.

Las huellas se han definido siguiendo la estandarización de términos establecida para las marcas de uso-desgaste reconocidas en ocres recuperados en sitios de la Edad de la Piedra Media en África (MSA) (Hodgskiss, 2010, 2013 y 2020; Rifkin, 2012).

Las hipótesis sobre la manipulación de que fueron objeto y sobre su posible funcionalidad se han sustenta- do en estudios experimentales replicativos y en comparaciones etnográficas y etnoarqueológicas (Hodgskiss, 2010, 2013; Rifkin, 2012; Rosso 2017b; Laborda, 2018).

\section{LAS MATERIAS PRIMAS}

La determinación de la composición geológica de los ocres ha sido realizada mediante un examen visual, sin aplicar ninguna técnica destructiva. El 47,05\% ( $n=$ 16) son materiales de matriz terroso-arcillosa y color rojizo. De ellos, 10 son masas de arcilla rubefactada, que contienen partículas de ocre agregadas; algunas de ellas parecen ser terrones de suelo aglutinados con materia colorante. Algo más de la mitad ( $n=18$, $52,94 \%$ ) son nódulos o fragmentos de nódulos siderítico-lutíticos (Figura 3).

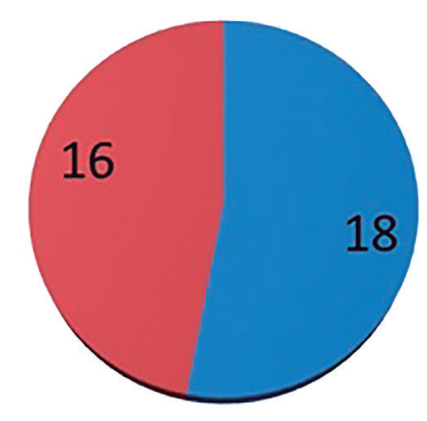

Nódulo lutítico Masa arcillosa roja

Fig.3. Composición geológica de los materiales colorantes. / Geological composition of the colouring materials.

\section{LOS OBJETOS MODIFICADOS}

En un $41,17 \%(n=14)$ hay evidencias de modificación antropogénica. De estos, 8 (23,52\% del total) tienen indudables signos diagnósticos de modificación por acción humana constatables en los cambios en la morfología y en las marcas de abrasión. En los otros 6 el origen de las trazas de modificación apreciadas puede someterse a una evaluación crítica. En los ejemplares en los que sólo se conservan áreas alisadas sin otros signos de uso-desgaste (estrías) cabría la posibilidad de que las alteraciones hayan tenido una causa accidental, por lo que, ante la ausencia de certezas absolutas, nos inclinamos por considerar sólo la probabilidad de la manipulación antrópica. El resto son fragmentos de masa colorante sin indicios de manipulación por uso (Tabla 2).

Destacamos la placa grabada con figuras de caballos en la que se reconocen, además de los surcos de la figuración, otros rastros de modificación desarrollados sobre su superficie. El resto los presentamos agrupados, considerando el tipo de traza que se ha producido en cada uno de ellos: molienda, rayado y alisado/frotado. 


\begin{tabular}{|c|c|c|c|c|c|c|}
\hline Profundidad & Nivel & Atribución cultural & Modificados & Posiblemente modificados & No modificados & Total \\
\hline $70 \mathrm{~cm}$ & B-C & Neolítico/Aziliense & 0 & 0 & 1 & 1 \\
\hline $90 \mathrm{~cm}$ & C & Magdaleniense final & 1 & 0 & 0 & 1 \\
\hline $95 \mathrm{~cm}$ & C & Magdaleniense final & 0 & 0 & 3 & 3 \\
\hline $110 \mathrm{~cm}$ & C & Magdaleniense final & 3 & 1 & 4 & 8 \\
\hline $120 \mathrm{~cm}$ & C & Magdaleniense final & 2 & 0 & 0 & 2 \\
\hline $145 \mathrm{~cm}$ & D & Magdaleniense superior & 0 & 4 & 11 & 15 \\
\hline $170 \mathrm{~cm}$ & E & Magdaleniense inferior & 2 & 0 & 1 & 3 \\
\hline \multirow[t]{2}{*}{$230 \mathrm{~cm}$} & $\mathrm{~F}$ & Magdaleniense inferior & 0 & 1 & 0 & 1 \\
\hline & & & 8 & 6 & 20 & 34 \\
\hline
\end{tabular}

Tabla 2: Grados de modificación por uso. / Degrees of modification due to use.

\subsection{Placa con caballos grabados (L.6C.120)}

La pieza se recuperó en tres fragmentos en la excavación de 1927. Dos de ellos se encontraron en una posición estratigráfica próxima, a una profundidad de 1,20 m, y el tercero, el de menor tamaño, a pocos centímetros en planta y profundidad de los primeros. Posteriormente, en un momento indeterminado, fueron lavados y unidos para reconstruir el formato original (Aranzadi y Barandiarán, 1927). La cota y la información gráfica publicada la sitúan en el relleno sedimentológico del estrato C (Magdaleniense) (Aranzadi y Barandiarán, 1935), posteriormente denominado nivel IV (Magdaleniense superior) (Barandiarán, 1967).

Fue publicada por los excavadores en sendas notas alusivas al descubrimiento de objetos de arte mueble en el País Vasco (Aranzadi y Barandiarán, 1927 y 1934). Con posterioridad ha sido analizada por diversos autores e incorporada a los catálogos de arte mueble cantábrico (Barandiarán, 1967 y 1973); Corchón, 1986; Apellániz, 1988; Altuna y Mariezkurrena, 2018, entre otros). El principal objeto de análisis han sido los trazos que componen las figuras grabadas, su ejecución y su estilo. El resto de las marcas han tenido una consideración secundaria. T. de Aranzadi y J.M. Barandiarán (1927: 6) señalaron para la cara que denominaremos reverso "se halla en parte desgastada artificialmente, formando una pequeña concavidad, lo cual es debido tal vez a que esta piedra sirvió de colorante". La asociación con el procesado del ocre también ha sido indicada por I. Barandiarán (1994) y D. Gárate (2013).

Se trata de un soporte cuadrangular de bordes

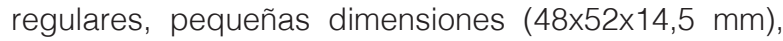
poco peso (38 g) y color rojo, con tono mate, sin brillo. La composición litológica muestra un grano muy fino, con textura compacta no terrosa, propia de un nódulo siderítico-lutítico ferroso. En la superficie de las caras no se aprecia porosidad, ni huellas por pérdida natural de grano. No muestra magnetismo, ni tiñe al contacto.

Los tres fragmentos en los que se recuperó han sido unidos y pegados por las líneas de fractura provocadas en la rotura. En el punto de unión de los fragmentos se observa una pérdida de masa. En los bordes de la pieza se han producido erosiones, ocasionadas por procesos postdeposionales, que han alterado la superficie generando pequeñas saltaduras escamosas, discontinuas e irregulares.

En las caras mayores, además de los surcos del grabado, hay claras marcas (estrías, microestrías y ranuras) que responden a patrones de desgaste producidos en el procesado de piezas de ocre mediante molienda (grinding), rayado (scoring) y frotado (rubbing) (Figura 4).
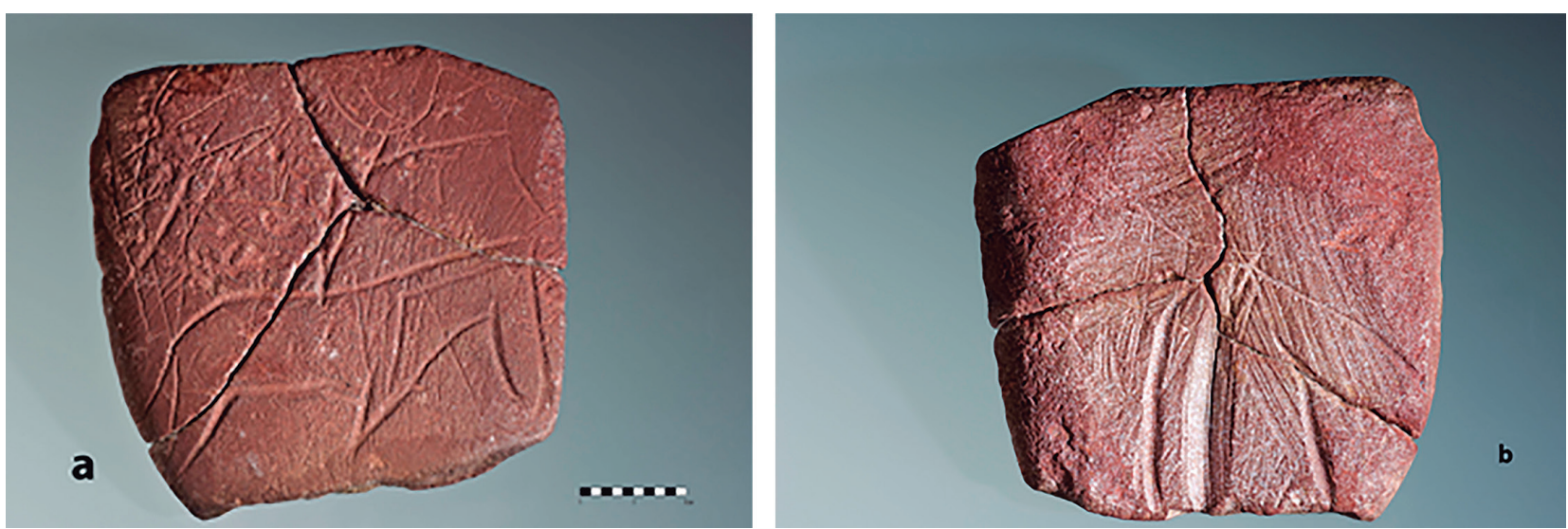

Fig.4. Anverso (a) y reverso (b) de la placa grabada (L.6C.120) (Santiago Yaniz, Arkeologi Museoa). / Obverse (a) and reverse (b) of the engraved slab (L.6C.120). (Santiago Yaniz, Arkeologi Museoa). 


\subsubsection{Anverso}

En la mitad derecha se aprecia una zona alisada con ligero nivelado de la microtopografía rugosa de la superficie, en la que se han generado series de estrías múltiples, paralelas entre sí, largas, rectilíneas y de orientación dispar. Las de la parte superior tienen una orientación oblicua al eje longitudinal y debieron alcanzar hasta el borde de la pieza. La trayectoria de las de la parte central e inferior es más vertical y no llegan a alcanzar el borde inferior de la placa. Son propias de una acción de raspado de la materia colorante sobre un elemento lítico rugoso y aplanado que produce efectos abrasivos. Las diferentes orientaciones indican cambios en la dirección del movimiento ejecutado, quizás en un mismo episodio de actividad (Figura 5a).

Las huellas de desgaste están atravesadas por los surcos que configuran el contorno de las figuras de los caballos grabados, lo que indica que la acción que las generó fue anterior a la realización de las figuras.

En el extremo superior izquierdo hay una maraña de incisiones y estrías de diferente intensidad que se entrecruzan, de forma anárquica, sin llegar a formar ninguna retícula o forma reconocible. En esa misma zona, se han producido levantamientos de contorno irregular, que rompen la trayectoria de algunos de los trazos incisos (Figura 5b).

\subsubsection{Reverso}

En la parte central del extremo superior se ha generado un hundimiento poco profundo de contorno oval. En el interior hay someras estrías rectilíneas paralelas, de perfil en $U$ y aristas redondeadas. La orientación de las estrías indica que el movimiento se efectuó en dirección perpendicular al eje axial.

La casi totalidad del resto de la cara está ocupado por un hundimiento de contorno subcuadrangular. En el interior se observan marcas lineales, entre las que distinguiremos, atendiendo a su grado de profundidad, estrías y ranuras. Usamos el término ranura en un sentido limitado para referirnos a incisiones de anchura y profundidad destacable, no en la significación más global empleada por Hosgdkiss (2010), que lo asimila a cualquier tipo de incisión o estría.

Las estrías de la parte derecha son paralelas, largas, de trayectoria recta y desarrollo continuo. La orientación muestra dos direcciones: una subparalela al eje longitudinal y otra ligeramente oblicua al mismo. La profundidad es homogénea, el perfil en $U$ con aristas simétricas y redondeadas. La fractura lateral derecha corta la continuidad de algunas de ellas de manera accidental (Figura 6a).

A la izquierda se distinguen series de desarrollo y trayectoria diversa, algunas paralelas y otras convergentes, que se cruzan y superponen. Parecen ser el resultado de acciones diferentes, desarrolladas con cambios de orientación y, quizás, de intensidad.

En la mitad inferior se localizan tres ranuras paralelas, de trayectoria rectilínea y dimensiones desiguales, que han abierto sendas hendiduras con una pérdida considerable de materia (Figura 6b).

La situada a la derecha (R1) es la de menor recorrido longitudinal de las tres. Se desarrolla desde la arista inferior de una de las fracturas hasta el borde inferior de

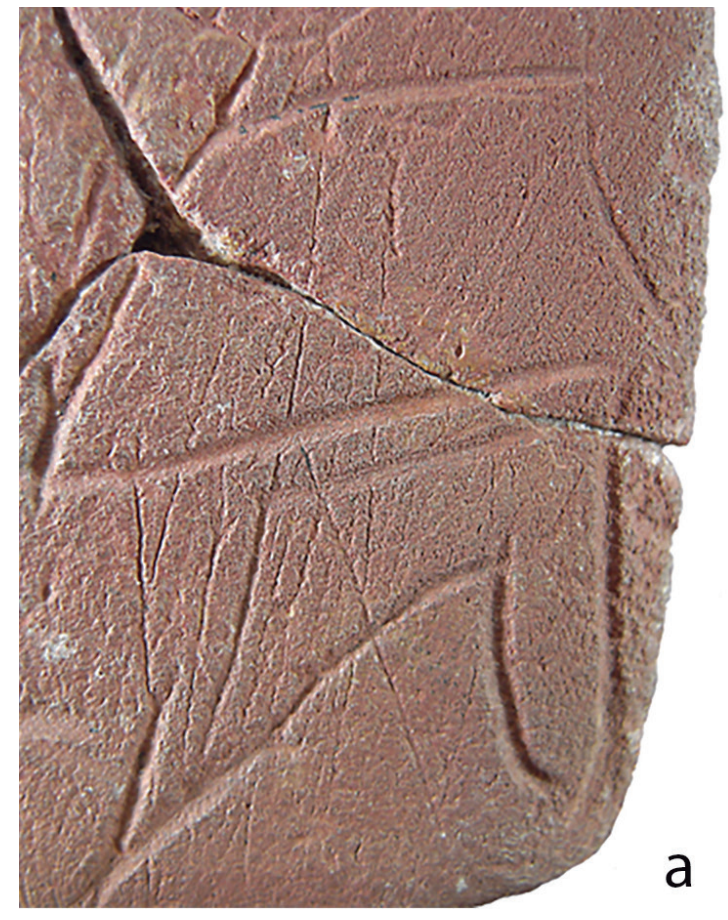

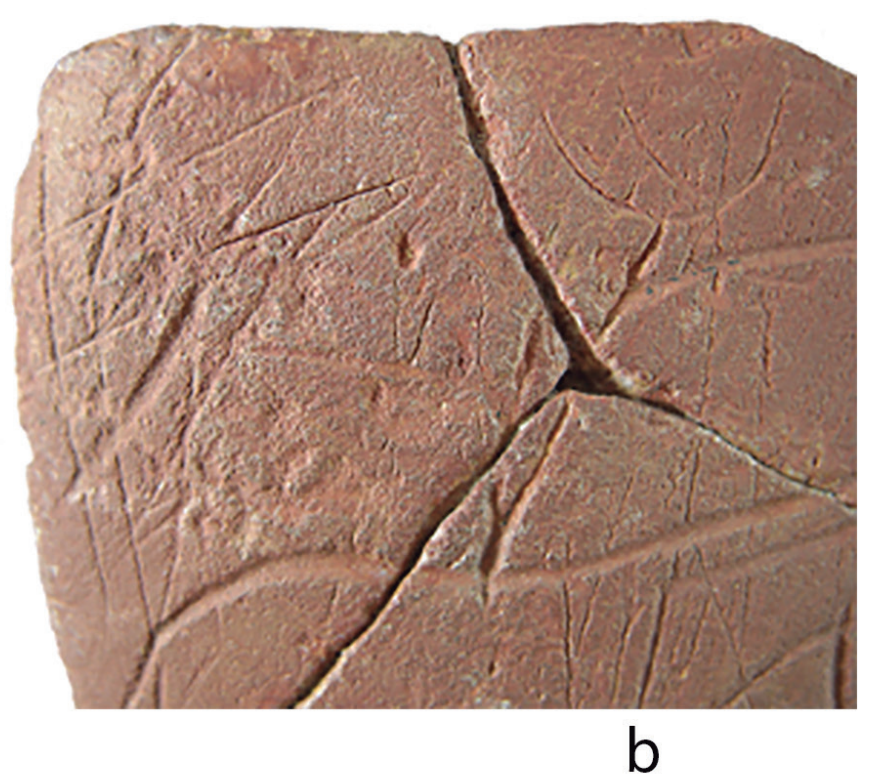

Fig.5. Detalle de las huellas de la mitad derecha del anverso (a) y del extremo superior izquierdo (b). / Detail of the prints on the right half of the obverse (a) and the upper left corner (b). 


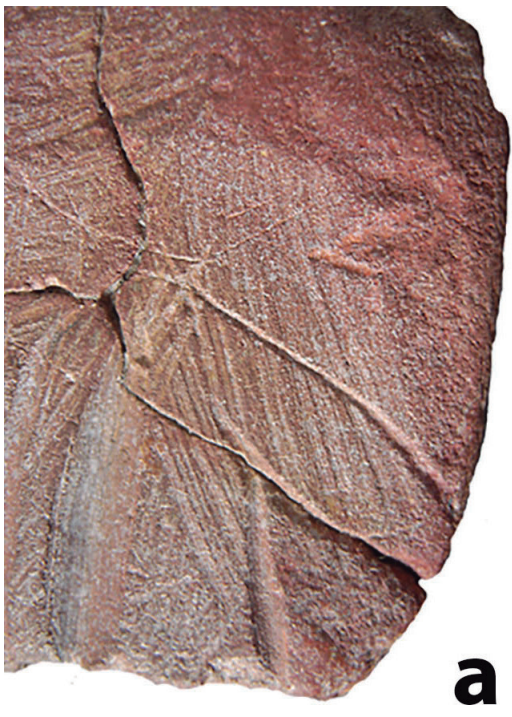

la placa, sin llegar a afectarlo. Es recta, más ancha en la parte central que en los extremos y de orientación levemente inclinada. El perfil tiene forma de $\mathrm{V}$ asimétrica y las aristas son redondeadas. Los extremos no están deshilachados. En el interior de las paredes de la acanaladura hay microestrías rectilíneas difusas.

La central (R2) es la de mayor anchura y profundidad. Discurre desde la zona central hasta el borde inferior, que modifica generando una hendidura. Es recta y paralela al eje axial. El perfil es en forma de $\mathrm{V}$ con paredes de inclinación desigual, más abierto hacia el lado derecho, y las aristas redondeadas. En las paredes y en el fondo se aprecian numerosas microestrías alargadas y rectilíneas, producidas por el movimiento cinético del instrumento lítico empleado para realizarla. El extremo superior del borde derecho se superpone a algunas de las estrías, lo que denota que el ranurado fue ejecutado con posterioridad al raspado.

La tercera (R3) se abre a la izquierda de la anterior y se desarrolla próxima a esta. Tiene uno de los extremos en la zona central, donde es posible que esté afectada por el deterioro ocasionado por la fractura. El extremo contrario se sitúa junto al borde inferior, sin alcanzarlo, ni modificarlo. La trayectoria es levemente sinuosa, con un cambio de sentido más acusado en la zona superior; la orientación paralela al eje central. El perfil se asemeja a una $U$ de paredes asimétricas, la izquierda más inclinada que la derecha. En las paredes y el fondo se han producido numerosas microestrías alargadas y rectilíneas.

Las tres ranuras son producto de una acción intensa y continuada de rayado realizada con un instrumento apuntado, quizás el diedro de un buril o el ápice de otro implemento lítico, que ha horadado la superficie con objeto de extraer partículas de materia.

El borde lateral izquierdo está modificado en su totalidad mediante un desgaste que ha ocasionado un plano biselado (Figura 7). En la superficie se ha producido una nivelación de la microtopografía de la roca y en el interior estrías aisladas y discontinuas de trayectoria corta y poca profunda. Estas huellas podrían interpretarse como consecuencia de una acción de frotado.

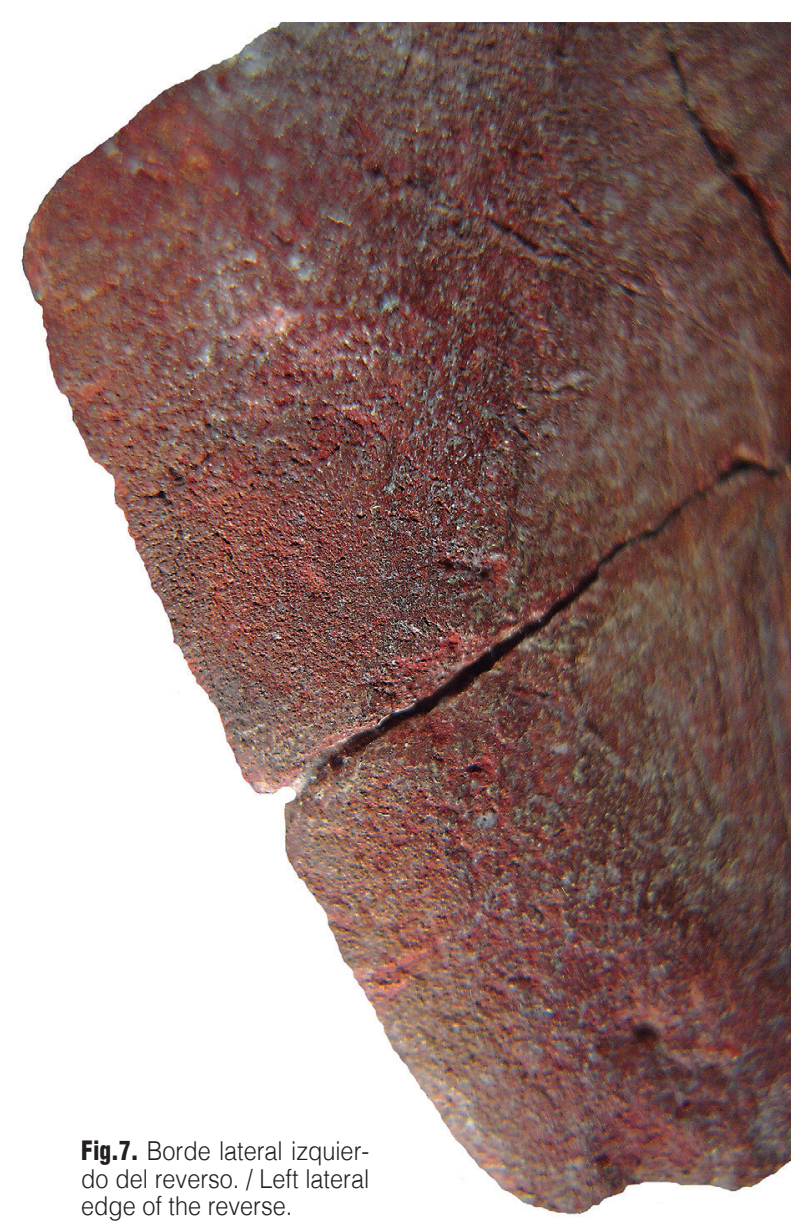




\subsection{Otros objetos modificados}

Presentamos la descripción de estos objetos en función de los patrones de desgaste reconocidos. En cada una de las categorías, el orden es el que marca la profundidad de techo a suelo registrada en la sigla.

\subsubsection{Molienda}

Dos piezas presentan patrones de desgaste indicativos de haber sido abrasionadas, dando como resultado la formación de superficies facetadas convergentes. Atendiendo a la forma que adquieren (facetada y modelada) los hemos considerado crayones (Watts, 2002; d'Errico, 2003; Rifkin, 2012).

L.12D.110.3. Fragmento de nódulo lutítico ( $28 \times 15 \times 12 \mathrm{~mm}$ y $4 \mathrm{~g}$ de peso), de color rojo con forma de prisma cuadrangular irregular con caras convexas y aristas redondeadas. Tiñe al contacto y no muestra signos de magnetismo. En varias de las caras y en el extremo superior se localizan rastros de uso-desgaste (Figura 8).

En la parte central del anverso hay tramos de superficie alisada sin estrías, que coinciden con zonas elevadas; en el borde derecho hay un estrecho y alargado plano de desgaste con estrías longitudinales, que se desarrolla en la arista de convergencia con la cara lateral derecha. En el reverso, ligeramente cóncavo, no se han producido modificaciones abrasivas.
Las caras laterales han experimentado una notable transformación con la formación de planos facetados. La derecha presenta una superficie ligeramente cóncava sobre la que se observan dos facetas desiguales, una que ocupa todo el espacio y otra, de pequeñas dimensiones y contorno triangular, que se localiza en el extremo superior derecho. Esta última ha erosionado la superficie de la anterior, por lo que cabe suponer que fue producto de un uso posterior. En el interior de ambas hay estrías regulares, largas, rectas y paralelas; las de la faceta triangular están menos marcadas. La cara izquierda tiene una configuración curvada y en ella se han desarrollado dos facetas que forman una leve arista en la línea de convergencia. La superficie de ambas está alisada y regularizada, sin estrías nítidas en su interior.

Las caras convergen en un bisel, truncado debido a un intenso desgaste posterior. Presenta una superficie plana, lisa y uniforme.

Las facetas y las estrías coinciden con las huellas ocasionadas en procesos experimentales por la molienda de ocres sobre soportes líticos. En ellos se ha demostrado que la morfología y las estrías macroscópicas son producto del frotado de nódulos sobre una piedra de afilar para obtener polvo de ocre (Wadley, 2005; Hodgskiss, 2013; Laborda, 2018).

Las áreas alisadas del anverso y la modificación que se ha producido en el ápice parecen responder a una actividad distinta, el frotado del ocre sobre una
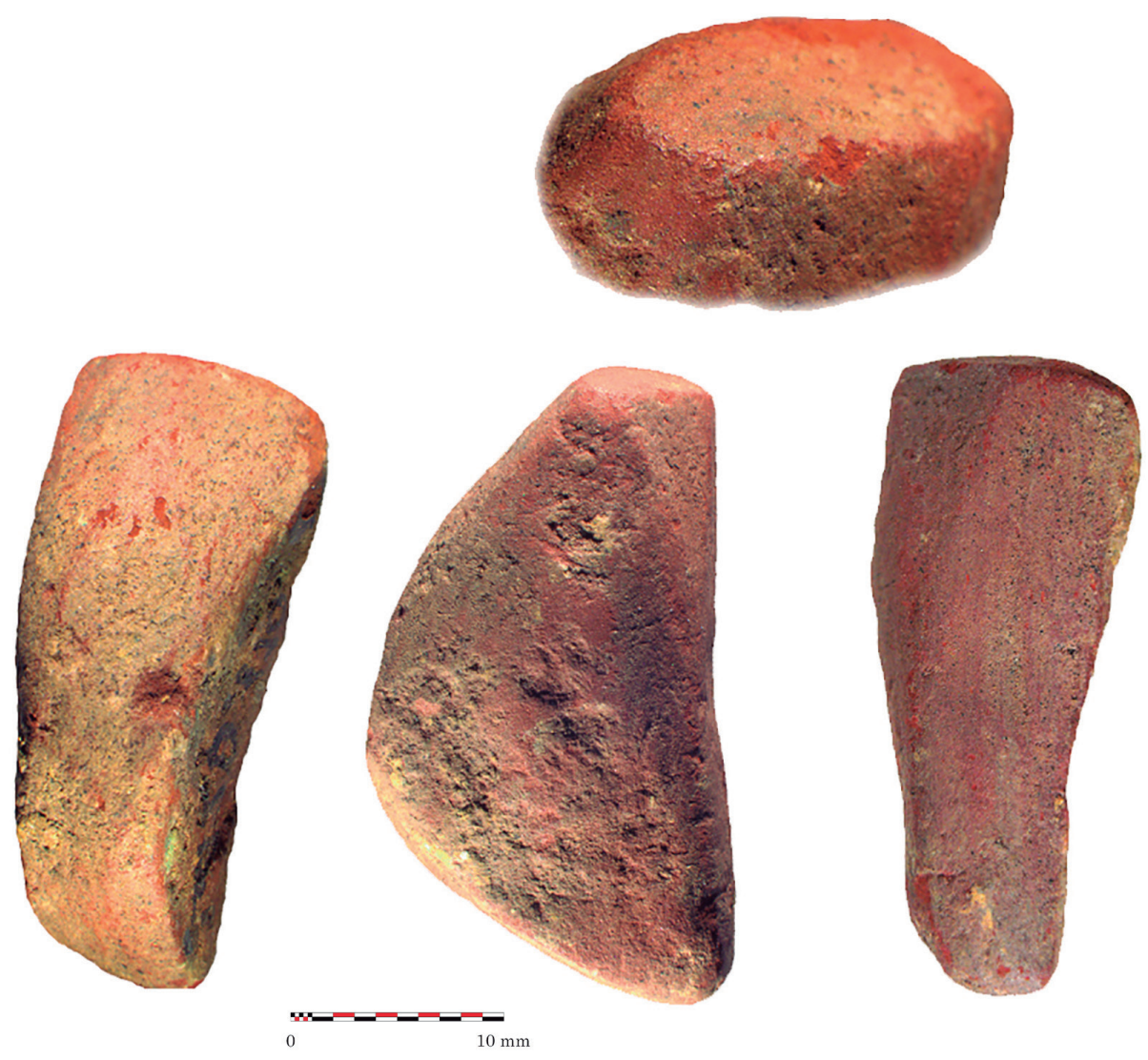

Fig.8. Crayón con desgastes por molienda (L.12D.110.3). / Crayon with wear due to grinding (L.12D.110.3) 
materia blanda, acción en la que el fragmento colorante sería aplicado con la intención de trasferir color o polvo (Hodgskiss, 2010). La combinación de huellas de diferentes características indica que con el mismo fragmento se llevaron a cabo estrategias de trabajo diversas y secuenciadas.

L.8F.170.1. Bloque lutítico de forma prismática piramidal con caras de tamaño desigual $(28,5 \times 27,7 \times 20,7$ $\mathrm{mm}$ y $25 \mathrm{~g}$ de peso). Color rojo mate con manchas negruzcas, masa compacta y pesada. No muestra signos de magnetismo y tiñe al contacto. Tiene saltaduras con forma de cráter de contorno irregular.

Todas las caras están facetadas y alisadas por desgaste. Convergen en un ápice distal apuntado, de arista rectilínea, no modificada (Figura 9a). El lateral derecho es de forma rectangular, con superficie muy nivelada (Fi- gura 9b). El izquierdo, por el contrario, tiene los límites desdibujados y en su mitad distal se aprecia un acusado plano de desgaste. En el interior de las caras se han formado estrías superficiales, en general cortas y longitudinales. La base también está alisada y en su interior hay estrías cortas, poco marcadas, de orientación anárquica.

\subsubsection{Rayado}

Esta actividad se ha identificado en dos placas de diferente formato en las que se aprecian series de incisiones de origen antropogénico.

L.12B.120.2. Fragmento rectangular de placa siderítico-lutítica de color rojo (23×12×4 mm y 2 g de peso) de caras lisas y bordes rectilíneos con aristas no redondeadas (Figura 10b)

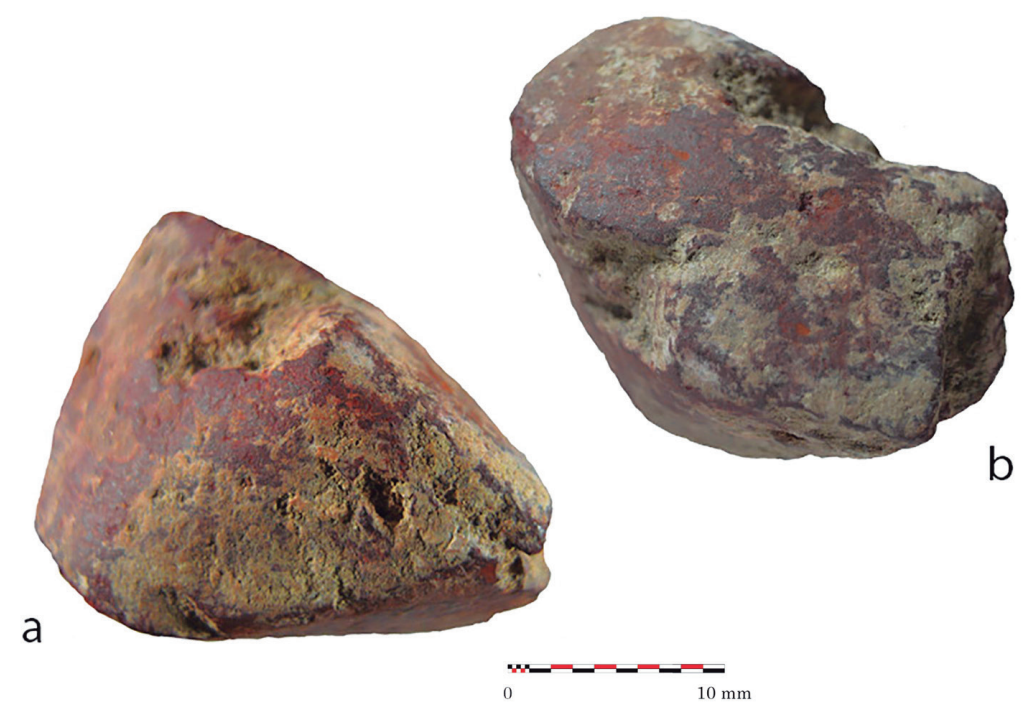

Fig.9. Crayón con desgastes por molienda (L.8F.170.1). / Crayon with wear due to grinding (L.8F.170.1).

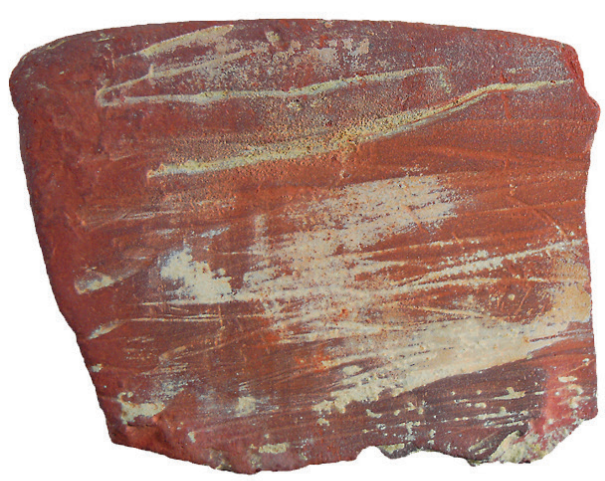

a

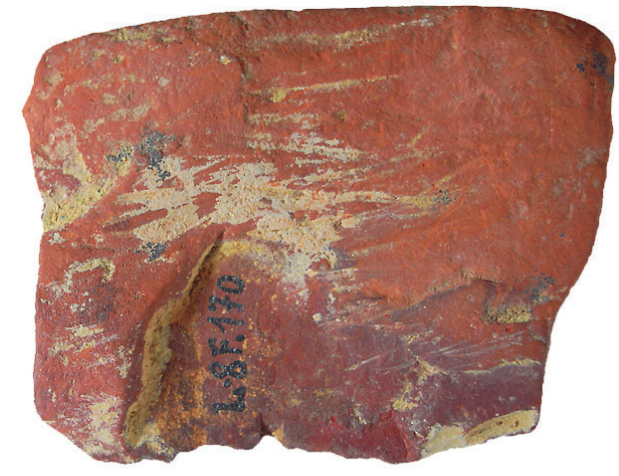

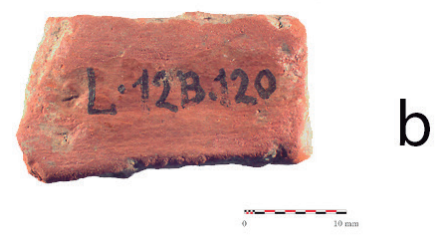

Fig.10. Placas con huellas de rayado: L.8F.170.2 (a); L.12B.120.2 (b). / Slabs with traces of scratching: L.8F.170.2 (a); L.12B.120.2 (b). 
El anverso tiene superficie lisa, ligeramente cóncava por desgaste funcional, con leves saltaduras accidentales postdeposicionales, que han levantado pequeñas partículas de materia. Sobre la superficie se observan numerosas incisiones poco profundas, perpendiculares al eje longitudinal, que se extienden de uno a otro extremo. Presentan perfil en $U$, con aristas redondeadas y finales no deshilachados. El reverso es irregular, con saltaduras y sin huellas de modificación.

L.8F.170.2. Fragmento cuadrangular de caras lisas (48×36x6 mm y $12 \mathrm{~g}$ de peso), de composición y color similar al anterior. Tres de los bordes tienen el trazado rectilíneo y la arista redondeada. El cuarto, el inferior, es sinuoso y está afectado por una saltadura. (Figura 10a).

Sobre ambas caras hay numerosas marcas lineales subparalelas, en algunos puntos convergentes, que se extienden a lo largo de casi toda la superficie. Las del anverso, rectilíneas, presentan distribución densa y desarrollo continuo. La mayor parte alcanzan el borde lateral derecho, sin deshilachados, pero no el izquierdo. La profundidad no es homogénea; predominan los surcos de sección en $U$ con fondo plano y aristas regulares. sobre los que la tienen en V. En el interior de algunas de ellas se aprecian microestrías.

En el reverso las estrías se distribuyen de forma discontinua; la mayor densidad se localiza en la zona central y en el cuarto inferior derecho, en el que algunas continúan sobre la superficie creada por la saltadura laminar, lo que indica que se produjeron con posterioridad a esta. De trayectoria recta y desarrollo continuo, presentan un recorrido más corto y una menor profundidad que las de la cara anterior. La orientación es similar a las del anverso. La sección en $U$ y $V$, con aristas regulares y microestrías en el interior (Figura 11).

En ambos objetos las huellas son el resultado de un movimiento de rayado o raspado orientado a la obtención de polvo de ocre. La acción debió de llevarse a cabo con el filo de un útil, que se ha aplicado mediante desplazamientos largos y continuos. Considerando la profundidad de las incisiones, podría suponerse que las de la placa L.8F.170.2 fueron realizadas con un utensilio lítico. Por el contrario, las de la primera, leves y superficiales, podrían responder al uso de un instrumento más blando, quizás de hueso o madera (Hodgskiss, 2010).

\subsubsection{Piezas alisadas/frotadas}

Nueve fragmentos de morfología diversa presentan áreas alisadas y niveladas, que contrastan con las irregularidades que se observan en el resto de la superficie. En ninguno se ha llegado a producir una alteración notable de la forma, ni la creación de planos facetados. Los experimentos replicativos muestran que este tipo de modificaciones se generan por una acción de frotado del material colorante contra una materia blanda, acción que producen marcas poco diagnósticas, sin

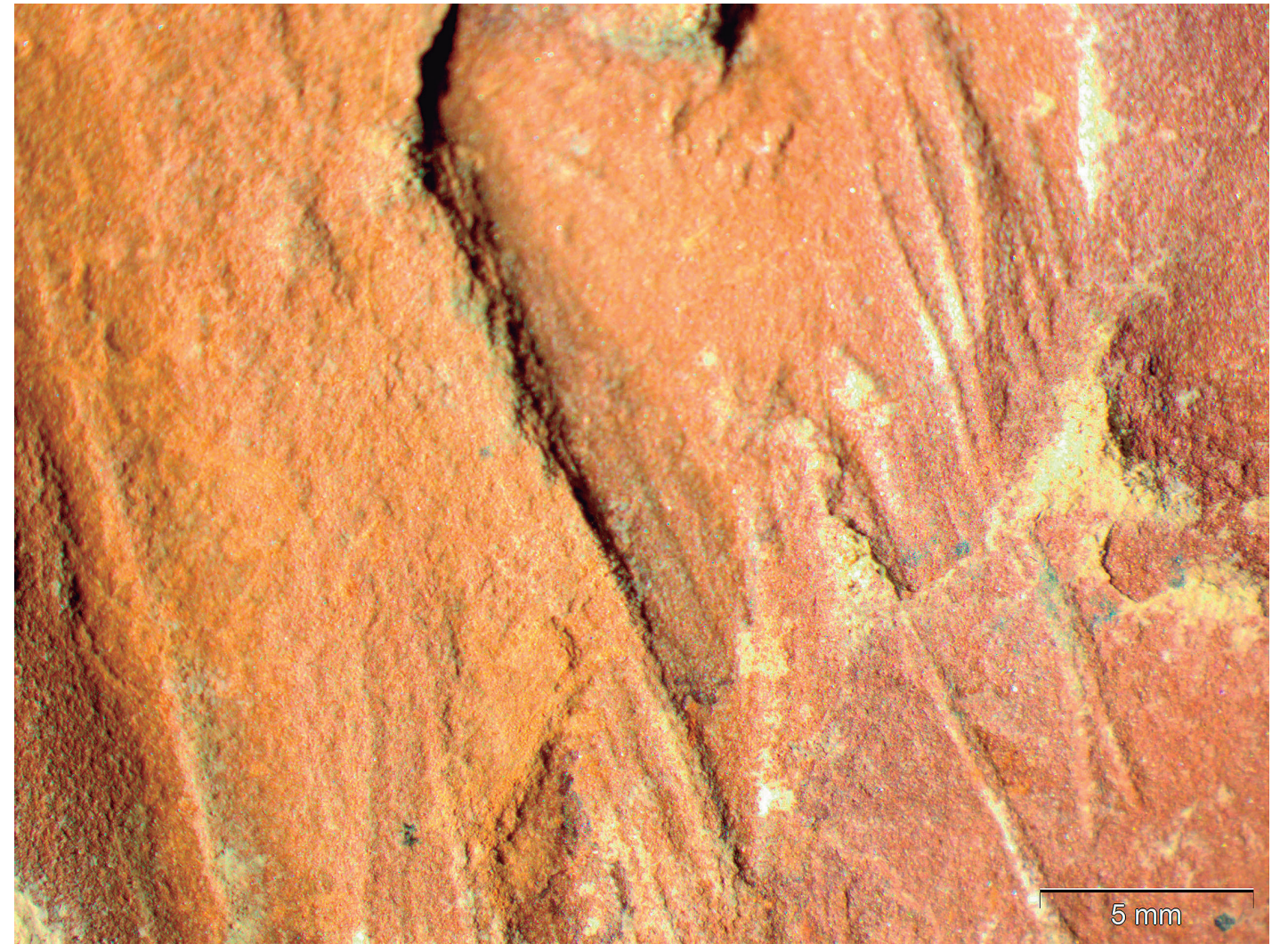

Fig.11. L. 8F.170.2. Detalle de las microestrías en surcos del reverso. L. 8F.170.2 .Detail of the micro-striations in the grooves of the reverse. 
rastros abrasivos severos, como la formación de facetas o de grupos de estrías profundas (García Díez et al, 2009; Hodgskiss, 2010; Rifkin 2012).

En tres de los objetos son perceptibles estrías alargadas en la zona desgastada. En el primero de ellos (L.12D.110.1) se ha generado una cara plana y alisada de aristas vivas en la que se observan microestrías longitudinales. Uno de los extremo de esa cara tiene forma redondeada (Figura. 12d). En el segundo (L.12E.110.1), la cara alisada tiene pequeñas irregularidades y oquedades, por lo que no muestra el aspecto de un plano completamente regularizado. Sobre los tramos lisos son visibles microestrías paralelas de orientación ligeramente oblicua con respecto al eje central (Figura 12 c). El tercero (L.5E.90.1), es un bloque prismático de base rectangular $(60 \times 37 \times 35 \mathrm{~mm})$ con un desgaste poco definido en el ápice y un nítido alisado en la base sobre la que se aprecian microestrías longitudinales (Figura 13).

Para los otros seis es problemático asociar, sin una valoración crítica, los rastros de alisado exclusivamente con procesos de manipulación antrópica. Cabe la posibilidad de que algunas de las superficies alisadas pudieran haberse ocasionado por procesos postdeposicionales. Por ello, a los objetos que carecen de estrías los consideramos "posiblemente modificados" (Velliki et al., 2018) o "posiblemente utilizados" (Hodgskiss, 2013, 2020).
Las prácticas experimentales y las analogías etnoarqueológicas atestiguan que las materias sobre las que se han podido aplicar de forma directa los fragmentos de colorante con superficies alisadas son la piel u otros elementos orgánicos como el pelo (Soressi y d’Errico 2007; Rosso, 2017b).

\section{VALORACIÓN DE LOS DATOS}

Los materiales colorantes forman parte del registro arqueológico de numerosos asentamientos del entorno cantábrico-pirenaico en el que se localiza la cueva de Lumentxa. La cantidad de hallazgos varía desde ejemplares únicos y excepcionales, hasta colecciones abundantes como las de Coimbre (Asturias) (García Madariaga et al., 2017) y Santa Catalina (Lekeitio, Bizkaia). Se asocian a contextos diversos: habitación, funerarios o de expresión artística. La cronología se extiende desde niveles musterienses hasta otros adscritos a las fases finales del Paleolítico superior, en los que aumentan las colecciones. La que estudiamos comprende un número considerable de piezas recuperadas en contextos magdalenienses y puede ponerse en relación con actividades domésticas o simbólicas.

Las piezas se distribuyen de forma desigual en la secuencia estratigráfica. Hay una notable concentración de objetos siglados entre los 90 y los $145 \mathrm{~cm}$ de profundidad, intervalo en el que se concentra el 85,29\% ( $n=$

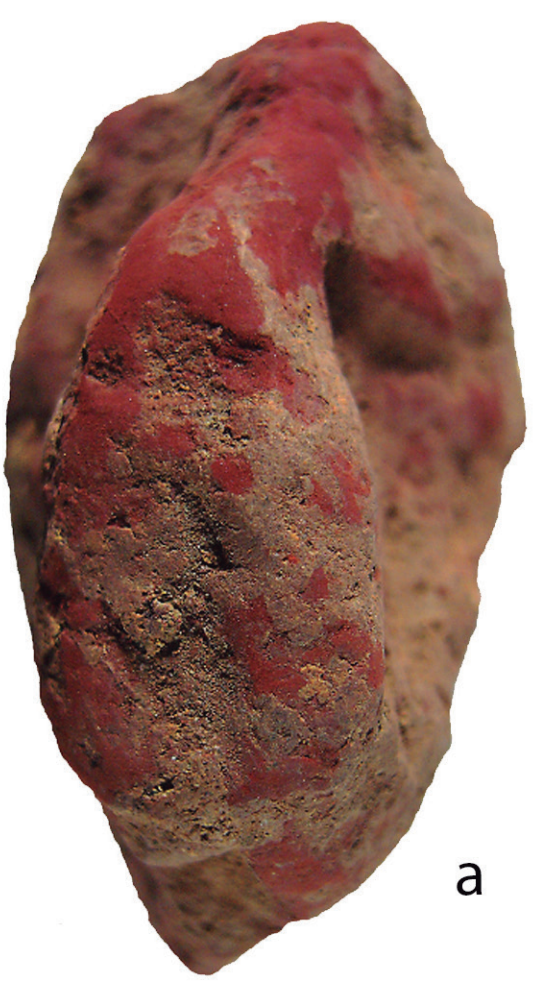

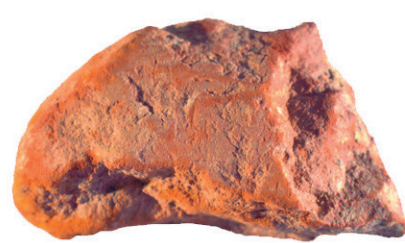

b

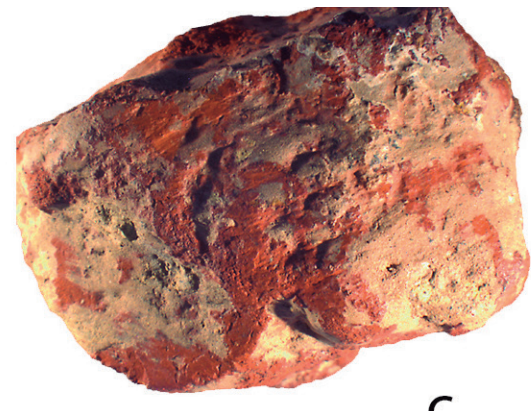

C
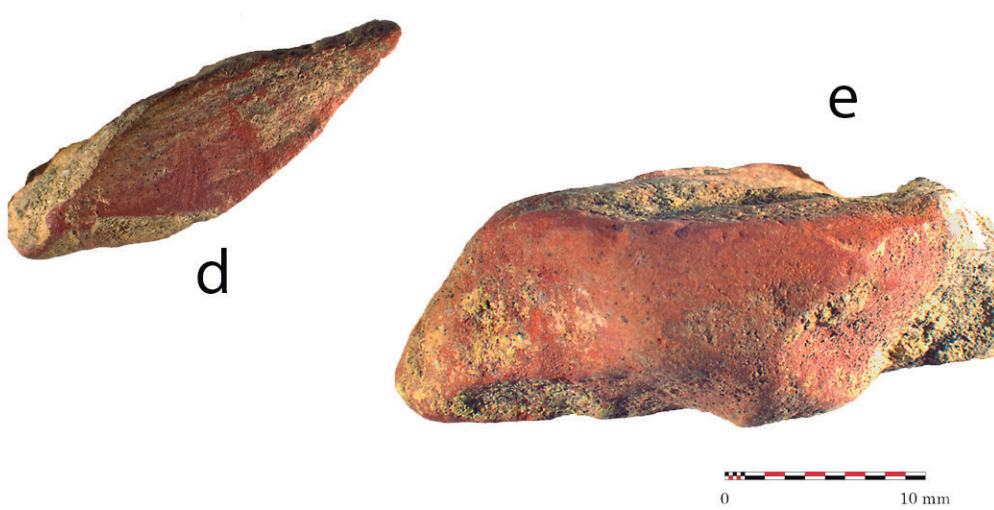

Fig.12. Fragmentos con huellas de alisado/frotado: L.6B.145.7 (a); L.6E.145.1 (b); L.12E.110.1 (c); L.12D.110.1 (d); L.12D.110.5 (e). / Fragments with traces of smoothing / rubbing: L.6B.145.7 (a); L.6E.145.1 (b); L.12E.110.1 (c); L.12D.110.1 (d); L.12D.110.5 (e). 


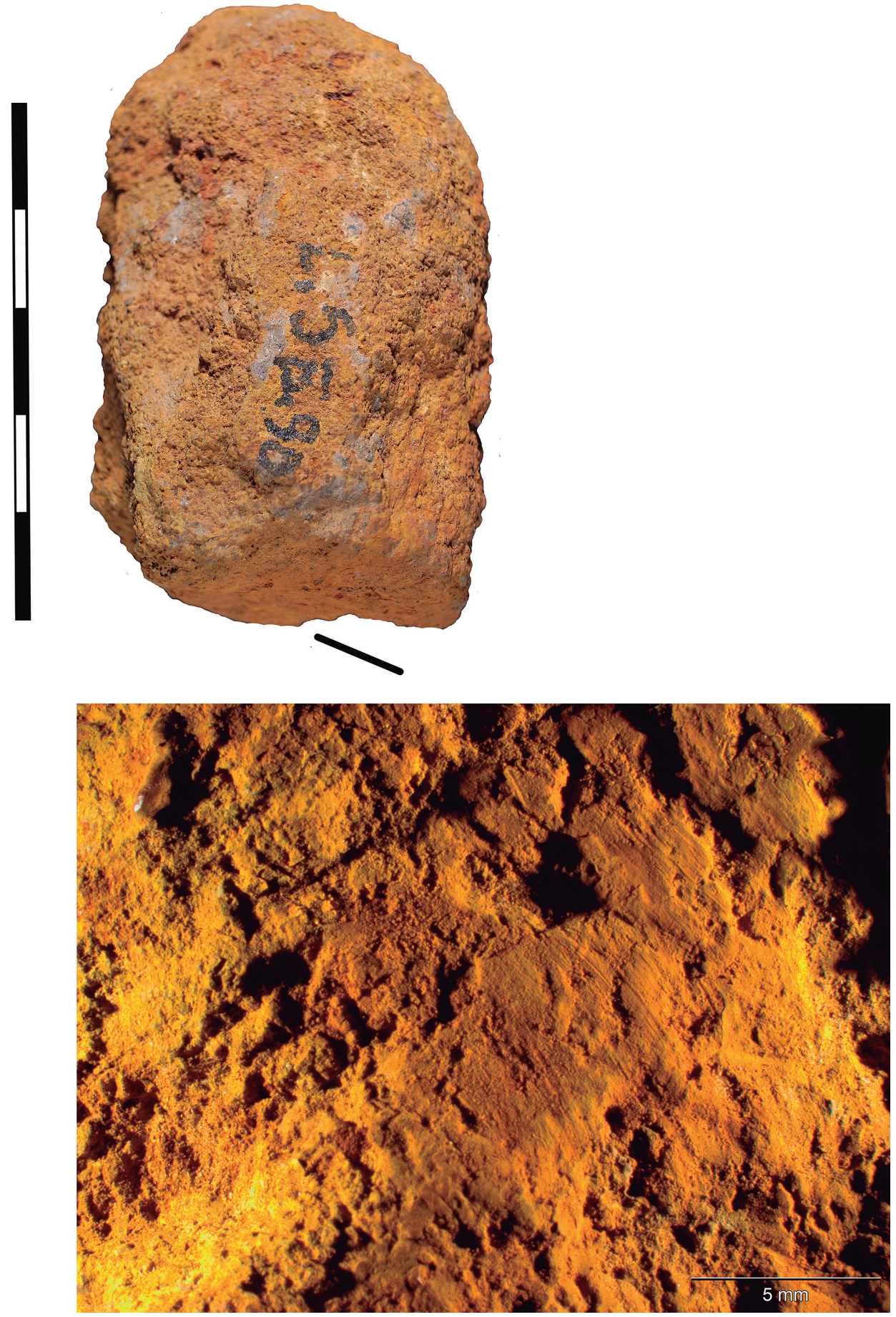

Fig.13. L.5E.90.1. Vista general y detalle de las microestrías en la base. / L.5E.90.1. General view and detail of the micro-striations on the base.
29). El porcentaje aún podría incrementarse si consideramos la información directa aportada por los excavadores para las tres piezas que tienen $170 \mathrm{~cm}$ de profundidad anotada en la sigla. De ellas se indica que fueron recuperadas "a profundidad de 1,20 m. al N. o 1,70 m. al S.". Idéntica información se puede leer en las anotaciones del diario de trabajo de J.M. de Barandiarán referidas al día 3 de septiembre de 1928: "Prof. 1,00-1,20 (a la izquierda es 1,50-1,70) (...). También salen hematites (una plaquita desgastada)". En esa misma profundidad se consigna el hallazgo de "punzones de hueso varios", que fueron siglados a profundidad de $120 \mathrm{~cm}$. Cabe, por tanto, un margen interpretativo sobre la posición exacta de estos ocres. Por debajo de la cota de $170 \mathrm{~cm}$ sólo se recuperó un ejemplar. De todo ello se desprende que la mayoría se acumula en los niveles que han sido asignados a las fases finales del Magdaleniense, en los que debió de ser intenso el procesado y uso del ocre. 
El análisis espacial de los hallazgos pone de manifiesto una notable agrupación en algunas zonas concretas del área excavada. Las referencias publicadas permiten situar con precisión los ocres en los tramos de excavación. De las 25 zanjas o trincheras que se abrieron, sólo en 6 se hallaron fragmentos colorantes, dándose el caso de que algunas de ellas son contiguas: la 5 y la 6; la 16, 17 y 18. En las zanjas 5 y 6 se recuperaron 12 ejemplares y 16 más sólo en la zanja 16. La conversión de esta estructura de trincheras en una planimetría de cuadrículas reprodujo la agrupación de los ocres en unos pocos cuadros, como se refleja en la sigla que les fue adjudicada. A los cuadros $12 \mathrm{D}, 12$ E y $12 \mathrm{~F}$ se adjudicaron los 12 objetos de las zanjas 5 y 6 y a los cuadros 6B, 6C y $6 \mathrm{E}$, los 16 de la zanja 16 . De esta concentración espacial podría inferirse que hubiera habido áreas de trabajo especializadas en el tratamiento de materias colorantes para su transformación o su uso. En este mismo sentido apunta la recuperación de algunos cantos teñidos con colorante en este mismo contexto estratigráfico.

De manera preliminar podemos intuir que los ocupantes de Lumentxa se abastecieron de materias loca- les, obtenidas en depósitos acumulados en los estratos geológicos del entorno litoral en el que se localiza el asentamiento Si consideramos la abundancia, proximidad y accesibilidad de afloramientos cretácicos de nódulos sideríticos situados en el extremo oriental de la playa de Karraspio (Mendexa), a escasos metros del asentamiento, la captación y el acarreo pudo hacerse con un bajo coste de energía (Figura.14).

Aunque no se ha realizado la determinación colorimétrica sobre la base de un código de colores estandarizado, la apreciación ocular permite indicar que el color exterior dominante es el rojo con tonalidades vivas o mates.

Está atestiguado por numerosas investigaciones que el tratamiento térmico de minerales ferruginosos de color amarillento o pardusco posibilita obtener pigmentos colorantes de color rojo (Pomies et al., 1999; Gialanella et al., 2011; Salomon et al. 2012; Álvarez Romero, 2012; Salomon et al., 2015; Cortell, 2016; Sindal, 2018). Si consideramos, a modo de hipótesis, que estas experiencias pueden servir de referencia para la interpretación de los ejemplares de Lumentxa, podríamos inferir que estos hubieran sido procesados con calor.

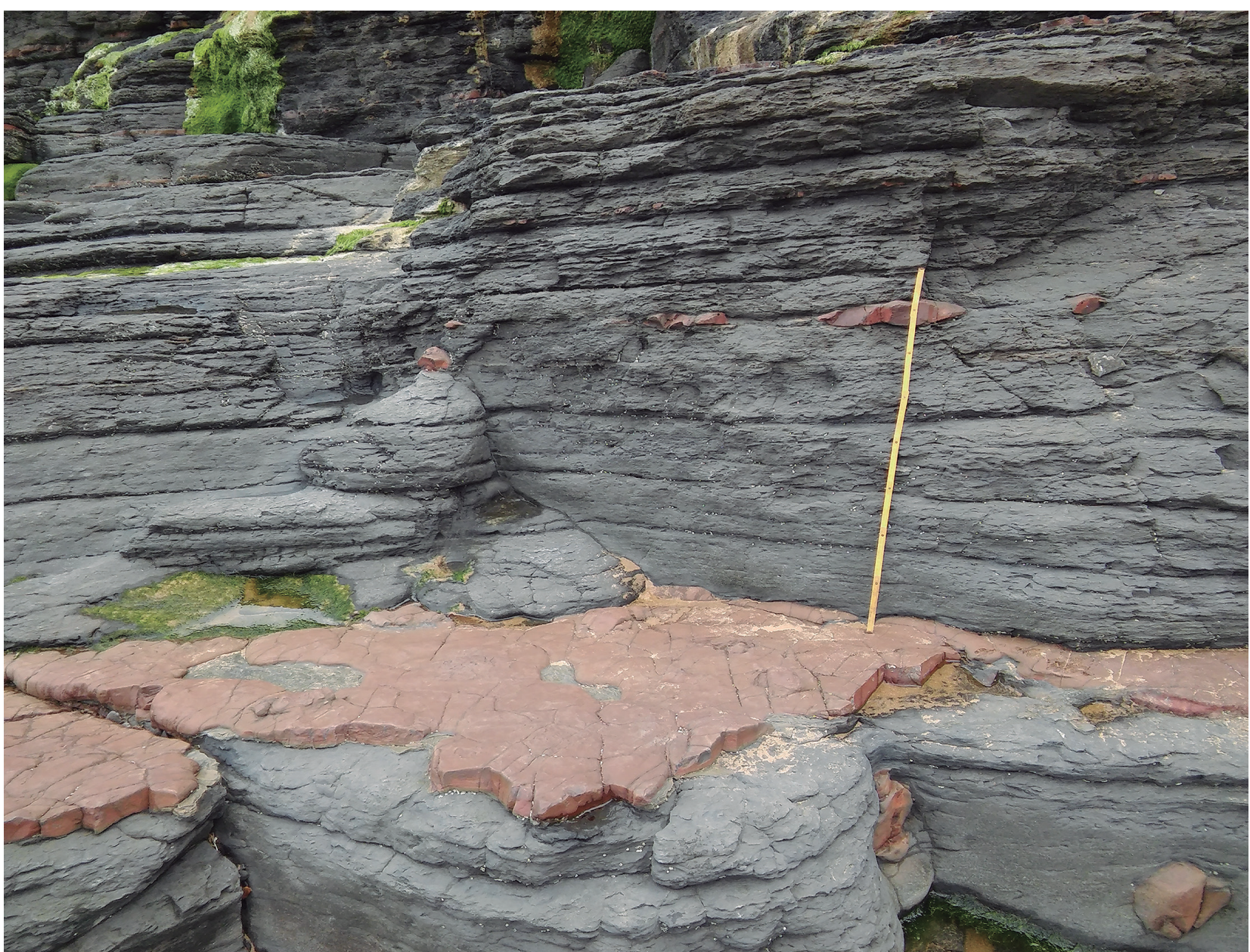

Fig.14. Afloramiento de nódulos sideritico-lutíticos en la playa de Karraspio (Mendexa). / Outcrop of siderite - lutite nodules on the beach of Karraspio (Mendexa) 
Los tipos de modificación que hemos determinado, considerando los patrones de desgaste, son: la molienda, el rayado, el alisado/frotado y el grabado (Tabla 3). En la mayoría de los objetos $(n=12)$ se reconocen huellas de un único tipo; sólo en dos se registran más de uno.

\begin{tabular}{|l|cccc|}
\hline \multicolumn{1}{|c|}{ Objeto } & Molienda & Rayado & Alisado/Frotado & Grabado \\
\hline L.5E.90.1 & & & $X$ & \\
L.12D.110.1 & & & $X$ & \\
L.12D.110.3 & $X$ & & $X$ & \\
L.12D.110.5 & & & $X$ & \\
L.12E.110.1 & & & $X$ & \\
L.6C.120 & $X$ & $X$ & $X$ & $X$ \\
L.12B.120.2 & & $X$ & & \\
L.6E.145.1 & & & $X$ & \\
L.6B.145.4 & & & $X$ & \\
L.6B.145.6 & & & $X$ & \\
L.6B.145.7 & & & $X$ & \\
L.8F.170.1 & $X$ & & & \\
L.8F.170.2 & & $X$ & & \\
L.11G.230.1 & & & $X$ & \\
& 3 & 3 & 11 & \\
\hline
\end{tabular}

Tabla 3: Patrones de desgaste en los objetos modificados. / Wear patterns on the modified artefacts.

La molienda fue la actividad que generó el modelado de las dos piezas definidas como crayón (L.12D.110.3 y L.8F.170.1) y la que se realizó sobre el anverso de la placa (L.6C.120) antes de ser grabada. El rayado provocó las incisiones y ranuras de las placas L.6C.120, L.12B.120.2 y L.8F.170.2. Las huellas que responden a patrones de alisado y/o frotado son las más repetidas. Se han reconocido como única traza en superficies lisas de nueve ejemplares. En tres de ellas se conservan estrías que podemos considerar generadas por el uso (L.5E.90.1, L.12D.110.1 y L.12E.110.5). También indican una acción de frotado las marcas reconocidas en el ápice y en algunas zonas del anverso de uno de los crayones (L.12D.110.3) y en un lateral de la placa grabada. Los restantes seis ejemplares carecen de evidencias rotundas que determinen el origen antrópico de las modificaciones. El grabado con la intención de configurar imágenes sólo se aplicó en la placa de los caballos.

Estos patrones de desgaste parecen indicar que la manipulación de los ocres se realizó para la obtención de polvo colorante por medio de la molienda y el rayado y para la aplicación de color sobre materias blandas por frotado.

Las piezas modeladas en forma de lápiz o crayón han sido interpretadas como elementos colorantes usados para aplicar color directamente sobre una superficie plana (Couraud, 1988; Soressi y d’Errico, 2007; Pradeau et al., 2014). Algunos trabajos experimentales han demostrado, por otra parte, que pueden ser un subproducto originado por la molienda de nódulos sobre muelas líticas para la obtención de polvo de ocre (Hodgskiss, 2013; Laborda, 2018).

El rayado y ranurado también permite conseguir polvo de ocre, si bien la cantidad obtenida es menor que la que produce la molienda, más eficiente para pulverizar la masa colorante (Hodgskiss, 2010).

Las marcas de frotado se producen por el roce directo del ocre sobre una superficie de poca intensidad abrasiva, generalmente orgánica (Hodgskiss, 2010; Rifkin, 2012). Esta podría haber sido la utilidad de los ejemplares en los que se han reconocido alisados y bordes redondeados, en algunos de ellos con huellas estriadas.

El empleo del ocre por las comunidades de cazadores-recolectores se ha asociado con múltiples actividades funcionales. Entre otras hipótesis, contrastadas mediante experimentos replicativos y analogías etnográficas, podemos citar su uso en la composición de adhesivos aplicados en la sujeción y ensamblaje de equipamientos líticos (Courand, 1988; Wadley, 2004 y 2005; Wadley et al., 2009; Kozowyk et al., 2016; Lombard, 2007), el procesado de la piel animal para su preservación y curtido (Audouin y Plisson, 1982; Rifkin, 2011; Roebroeks et al., 2012), el efecto antibacteriano, la protección de la piel humana del sol y de la picadura de los insectos (Velo, 1984; Rifkin et al, 2015; Ropebroeks, 2015). Asimismo se ha asociado con la manifestación de comportamientos simbólicos y estéticos (Watts 2002 y 2009; d’Errico, 2008; Henshilwood et al., 2009; Straus et al., 2015; Hoffmann et al., 2018), si bien es muy posible que determinadas aplicaciones funcionales no tuvieran un exclusivo uso utilitario y pudieran ser compatibles con un sentido simbólico (Lombart, 2007; Soressi y d’Errico, 2007; Cortell, 2016).

¿Cuál pudo ser la finalidad del procesado del ocre en la cueva de Lumentxa?. No descartamos ninguna de las utilidades domésticas indicadas, esenciales para la supervivencia de las comunidades de cazadores-recolectores. Se ha constatado experimentalmente que se requieren cantidades desiguales de colorante para cada una de ellas. Así, el curtido de las pieles y la protección contra los efectos del sol o de los mosquitos consumen una masa considerable de polvo de ocre (Rifkin, 2011). Por el contrario, actividades simbólicas como la pintura corporal o la realización de motivos se pueden conseguir con cantidades más reducidas (Watts, 2010; Rifkin, 2012), al igual que la adición a adhesivos para la sujeción de instrumentos a enmangues (Wadley, 2010).

Hemos reconocido en cinco cantos rodados que pueden ser asignados a niveles magdalenienses residuos de colorante rojo asociados a huellas de impacto y/o desgaste. Las primeras son indicativas de su uso en acciones de machacado o molienda de materias minerales duras y las segundas de un movimiento de 
fricción en contacto con el pigmento. Han sido relacionados con las cadenas operativas del procesado de minerales y del trabajo de la piel con adición de ocre (González e Ibáñez, 2002).

Por otra parte, en diferentes zonas del recorrido de la cueva se han localizado figuras, trazos y manchas pintadas en rojo (Gárate et al., 2013), por lo que cabría suponer que también se buscaría la obtención de pigmentos pictóricos para la ejecución de representaciones gráficas.

\section{CONCLUSIONES}

La revisión de las colecciones procedentes de las intervenciones históricas en el yacimiento de Lumentxa ha permitido analizar el conjunto de materias colorantes con componente ferruginoso recuperado en niveles atribuidos a diferentes fases del Magdaleniense. La mayor cantidad de ejemplares proceden de ocupaciones de los momentos finales de este período cronocultural. Se ha estudiado una cantidad considerable de restos, de los que algo más de un tercio conservan huellas de uso ocasionadas por manipulación antropogénica. Hay que considerar que el conjunto recuperado, a juzgar por la ausencia de residuos de pequeño tamaño, muy probablemente, es una representación parcial de las evidencias de ocre acumuladas en el yacimiento.

El ocre fue un recurso usual y recurrente en el equipamiento de los grupos que ocuparon Lumentxa durante el Magdaleniense. La captación del material pudo hacerse en formaciones geológicas muy cercanas al asentamiento, en las que son abundantes las vetas de nódulos lutíticos.

Los objetos recuperados fueron procesados mediante técnicas de reducción por desgaste (abrasión y rayado) para la obtención de polvo de ocre. Las huellas reconocidas en ellos también apuntan a un frotado directo sobre materias orgánicas blandas con finalidades funcionales u ornamentales. La adherencia de ocre en artefactos macrolíticos con signos de modificación por uso, induce a pensar en acciones de fracturación y machacado de material colorante.

Podemos vincular el uso potencial de los colorantes con actividades relevantes de carácter doméstico y/o simbólico como el enmangue de artefactos líticos, el trabajo de la piel, o la pintura corporal, de las que no permanecen vestigios materiales en el registro arqueológico, si bien algunas de ellas pueden ser reconocidas en los tipos de implementos líticos tallados y en los artefactos macrolíticos recuperados en los niveles magdalenienses. Por último, es patente su relación con la expresión gráfica. Esta se constata en la elección de un nódulo siderítico-lutítico, que había servido para la obtención de polvo de ocre, como soporte para la representación de figuras de caballos grabadas o en el empleo de pigmentos de color rojo para las representaciones pictóricas realizadas en las paredes de la cavidad.

\section{BIBLIOGRAFÍA}

Altuna, J., Mariezkurrena, K., 2018. Hueso trabajado. Adornos y arte mobiliario en la Prehistoria paleolítica vasca. Eusko Jaurlaritza-Gobierno Vasco.

Álvarez Romero, C., 2012. Los pigmentos en la prehistoria: proyecto de experimentación térmica con óxidos e hidróxidos de hierro. Boletín de Arqueología experimental 9, 25-42.

Apellániz, J.M., 1988. La plaquette à chevaux hypertrophiques de Lumentxa (Biscaye) et les styles du Magdalénien supérieur/ final dans le Pays Basque. Munibe Antropologia-Arkeologia 40, 9-14.

Aranzadi, T., 1929. Restos humanos de las cavernas de Santimamiñe (Cortézubi), Arezti (Ereño) y Lumentxa (Lequeitio) en Vizcaya. En: Duodécimo Congreso de la Asociación Española para el Progreso de las Ciencias, 71-98. Ed. Hilarion Eslava 5, Madrid (España).

Aranzadi, T., Barandiaran, J.M., 1927. Nuevos hallazgos de arte magdaleniense en Vizcaya. Investigaciones prehistóricas. Anuario de la Sociedad de Eusko-Folklore 7, 3-6.

Aranzadi, T., Barandiaran, J.M., 1934. Contribución al estudio del arte moviliar magdalaniense del país vasco. Anuario de Eusko Folklore 14, 213-234.

Aranzadi, T., Barandiaran, J.M., 1935. Exploraciones en la caverna de Santimamiñe (Basondo:Cortézubi). Tercera memoria, yacimientos Azilienses y Paleolíticos. Exploraciones de la caverna de Lumentxa (Lekeitio). Excma. Diputación de Vizcaya, Bilbao.

Arias, P., Laval, E., Menu, M., González Sainz, C., Ontañón R., 2011. Les colorants dans l'art pariétal et mobilier paléolithique de La Garma (Cantabrie, Espagne). L'anthropologie 115, 425-445.

Arribas, J.L., 1997. Materiales romanos de la cueva de Lumentxa (Lekeitio, Bizkaia). Isturitz, Cuadernos de prehistoria-arqueología 9, 643-656.

Arribas, J.L., 2004. Los asentamientos del Magdaleniense Superior-Final en la cuenca del río Lea. En: Berganza, E., Ruiz, R., Una piedra, un mundo. Un percutor magdaleniense decorado, 23-36. Diputación Foral de Álava. Vitoria-Gasteiz.

Arribas, J.L., Berganza, E., 2018. Excavaciones en la cueva de Lumentxa (Lekeitio, Bizkaia). Campañas de 1984 a 1993. Kobie Serie Paleoantropología 36, 31-56.

Audouin, F., Plisson, H., 1982. Les ochres et leurs témoins au Paléolithique en France: Enquéte et expériences sur leur validité archéologique. Cahiers du Centre de Recherches Préhistoriques 8, 33-80.

Aura Tortosa J.E., Gallello, G., Roldán C., Cavallo, G., Pastor A., Murcia-Mascarós S., 2020. Characterization and sources of Paleolithic-Mesolithic ochre from Coves de Santa Maira (Valencian Region, Spain). Geoarchaeology 36, 72-91. https://doi. org/10.1002/gea.21821

Barandiaran, J.M., 1965. Excavaciones en Lumentxa (Campaña 1963). Noticiario Arqueológico Hispánico VII, 56-61.

Barandiaran, J.M., 1966. Excavaciones en Lumentxa (Campaña 1964). Noticiario Arqueológico Hispánico VIII/IX, 24-32.

Barandiaran Maestu, I., 1967. El Paleomesolítico del Pirineo Occidental. Bases para una sistematización tipológica del instrumental óseo paleolítico. Monografías Arqueológicas 3. 
Barandiaran Maestu, I., 1973. Arte mueble del Paleolítico cantábrico. Monografías Arqueológicas de la Universidad de Zaragoza 14.

Barandiaran Maestu, I., 1994. "Arte mueble del Paleolítico cantábrico: una visión de síntesis. Complutum 5, 45-79.

Berganza, E., Arribas, J.L. (Coords.), 1994. El asentamiento paleolítico de Laminak II (Berriatua, Bizkaia)". Kobie Serie Paleoantropología 21, 5-253.

Berganza, E., Arribas, J.L. (Coords.), 2014. La intervención arqueológica en el yacimiento de la cueva de Santa Catalina. Kobie, serie BAI 4.

Berganza, E., Arribas, J. L., Castaños, P., Elorza, M., González Urquijo, J. E., Ibáñez, J. J., Iriarte, M. J., Morales, A., Pemán, E., Rosales, T., Roselló, E., Ruiz Idarraga, R., Uriz, A., Uzquiano, P., Vásquez, V., Zapata, L., 2012. La transición tardiglaciar en la costa oriental de Bizkaia: el yacimiento de Santa Catalina. Resultados preliminares. En: Arias Cabal, P., Corchón Rodríguez, M.S., Menéndez Fernández, M., Rodríguez Asensio, J.A. (Eds.), El Paleolítico Superior Cantábrico. Actas de la la Mesa Redonda (San Román de Candamo 26-28 abril 2007), 171 182. Universidad de Cantabria. Santander.

Berganza, E., Arribas, J.L., Ruiz Idarraga, R., 2012. Estudio tecnológico de los moluscos marinos perforados de los yacimientos de Lumentxa y Santa Catalina (Lekeitio, Bizkaia). Munibe 63, 93-104.

Corchón Rodríguez, S., 1986. El arte mueble paleolítico cantábrico. Contexto y análisis interno. Centro de Investigación y Museo de Altamira, monografías $n^{\circ} 16$. Ministerio de Cultura, Madrid.

Cortell, A., 2016. El ocre en la Prehistoria: entre la funcionalidad y el simbolismo. Archivo de Prehistoria Levantina XXXI, 187-211.

Couraud, C., 1988. Pigments utilisés en Préhistoire. Provenance, préparation, mode d'utilisation. L'Anthropologie 92, 17-28.

D'Errico, F., 2003. The Invisible Frontier. A Multiple Species Model for the Origin of Behavioral Modernity. Evolutionary Anthropology 12, 188-202.

D'Errico, F., 2008. Le rouge et le noir: implications of early pigment use in Africa, the near East and Europe for the origin of cultural modernity. Goodwin Series 10, 168-174.

D’Errico, F., Salomon, H., Vignaud, C., Stringer, C., 2010. Pigments from the Middle Palaeolithic levels of Es-Skhul (Mount Carmel, Israel). Journal of Archaeological Science 37, 30993110.

García Díez, M.; Aubry, T. y Sampaio, J. D. 2009 "Los materiales colorantes en los yacimientos pleistocenos del Valle del Côa: Quinta da Barca Sul, Olga Grande 4 y Cardina I", en AUBRY, T. (Ed.), 200 séculos da historia do Vale do Côa: incursões na vida quotidiana dos caçadores -artistas do Paleolítico-, Trabalhos de Arqueologia, 52, 395-435.

García Madariaga, M., García Diez, M., Álvarez Alonso, D., 2017. Los materiales colorantes del depósito arqueológico de la zona B de la cueva de Coímbre (Peñamellera Alta, Asturias). En: Yravedra Sainz de los Terreros J., Álvarez Alonso, D. (Dir.), La cueva de Coímbre (Peñamellera Alta, Asturias): ocupaciones humanas en el Valle del Cares durante el Paleolítico superior 518-523.

García-Sagastibelza, A., Arribas, J.L., López-Onaindia, D., Pomeroy, E., Rodríguez-Hidalgo, A., Castex, D., Couture-Veschambre, Ch., Gómez-Olivencia, A., 2020. The human remains from the Lumentxa cave (Lekeitio, Biscay, Northern Iberian Peninsula): Paleobiology, Taphonomy and Chronology. Quaternary International 566-567, 191-210.

Gárate, D., 2012. Neandertales y Cromañones. Primeros habitantes de Bizkaia. Guías del Arkeologi Museoa, 2. Paleolítico. Arkeologi Museoa. Bilbao.

Gárate Maidagan, D., Rios Garaizar, J., Ruiz Redondo, A., 2013. El arte parietal paleolítico de la cueva de Lumentxa (Lekeitio, Bizkaia). Kobie Paleoantropología 32, 5-28.

Gialanella, S., Belli, R., Dalmeri, G., Lonardelli, I., Mattarelli, M., Montagna, M., Toniutti, L., 2011. Artificial or natural origin of hematite-based red pigments in archaeological contexts: the case of Riparo Dalmeri (Trento, Italy). Archaeometry 53 (5), 950-962.

González Echegaray, P. J., García Guinea, M. A., Beguines, A., Madariaga de la Campa, B., 1963. La cueva de La Chora (Santander). Excavaciones Arqueológicas en España 26.

González Sainz, C., 1989. El Magdaleniense superior final de la región cantábrica. Ed. Tantín, Santander.

González Urquijo, J.E., Ibáñez, J.J., 2002. The use of pebbles in Eastern Vizcaya between 12000 and 10000 BP. In : Procopiou, H., Treuil, R. (eds.), Moudre et Broyer. L'interpretation fonctionelle de l'outillage dans le Préhistoire et l'Antiquité. Actas de la tabla redonda internacional v. 2, 69-80.

Groenen, M., 1991. Présence de matières colorantes dans I'Europe paléolithique. Anthropologie et Préhistoire 102, 9-28.

Henshilwood, C. S., D'Errico, F., Watts, I., 2009. Engraved ochres from the Middle Stone Age levels at Blombos Cave, South Africa. Journal of Human Evolution 57, 27-47.

Hodgskiss, T., 2010. Identifying grinding, scoring and rubbing use-wear on experimental ochre pieces. Journal of Archaeological Science 37, 3344-3358.

Hodgskiss, T., 2013. Ochre Use in the Middle Stone Age at Sibudu, Sou th Africa: Grinding, Rubbing, Scoring and Engraving. Journal of African Archaeology 11 (1), 75-95.

Hodgskiss, T., 2020. Ochre Use in the Middle Stone Age". https://doi.org/10.1093/acrefore/9780190854584.013.51

Hoffmann, D.L., Standish, C.D., García-Diez, M., Pettitt, P.B., Milton, J.A., Zilhão, J., Alcolea-González, J.J., Cantalejo-Duarte, P., Collado, H., Balbín, R. de, Lorblanchet, M., Ramos-Muñoz, J., Weniger, G.-Ch., Pike, A.W.G., 2018. U-Th dating of carbonate crusts reveals Neandertal origin of Iberian cave art. Science 359, 912-915.

Kozowyk, P.R.B., Langejans, G.H.J., Poulis, J.A., 2016. Lap Shear and Impact Testing of Ochre and Beeswax in Experimental Middle Stone Age Compound Adhesives. PLoS ONE 11, (3): e0150436. https:/doi.org/10.1371/journal.pone.0150436

Laborda Martínez, M. A., 2018. Análisis traceológico de una muestra de hematites y ocres con estigmas de utilización recuperados en la cueva de Zatoya (Abaurrea Alta, Navarra). Aproximación a los modos de uso y a su posible utilidad. Cuadernos de Arqueología 26, 129-182.

Lombard, M., 2007. The gripping nature of ochre: the association of ochre with Howiesons Poort adhesives and Later Stone Age mastics from South Africa. Journal of Human Evolution 53, 406-419.

Normand, Ch., 2017. Les matiéres colorantes minérales des fouilles E. Passemard et S. Saint-Périer dans la grotte d'Isturitz (collections du MAN). In : Normand, C., Cattellain, P. (Eds.), La 
grotte d'Isturitz. Fouilles anciennes et récentes. Actes de la table ronde du cinquantenaire du classement comme Monument Historique des grottes d'Isturitz et d'Oxocelhaya. Artefacts 13, 25-34.

Pradeau, J.V., Salomon, H., Bon, F., Mensan, R., Lejay, M., Regert, M., 2014. Les matières colorantes sur le site de plein air aurignacien de Régismont-le-Haut (Poilhes, Hérault). Acquisition, transformations et utilisations. BSPF 111(4), 631-658.

Peresani, M., Vanhaeren, M., Quaggiotto, E., Queffelec, A., D'Errico, F., 2013. An Ochered Fossil Marine Shell From the Mousterian of Fumane Cave, Italy. PLoS ONE 8 (7): e68572. https://doi.org/10.1371/journal.pone.0068572

Pomiès, M.P., Barbaza, M., Menu, M., Vignaud, C., 1999. Préparation des pigments rouges préhistoriques par chauffage. L'Anthropologie 103(4), 503-518.

Queffelec A., D’Errico, F., Vanhaeren, M., 2017. Analyse des blocs de matière colorante de Praileaitz I (Deba, Gipuzkoa). En : Peñalver, J., San José, S., Mujika, J.A. (eds.), La Cueva de Praileaitz I (Deba, Gipuzkoa, Euskal Herria). Intervención arqueológica 2000-2009, Munibe Monographs. Antropology and Archaeology Series 1, 493-503.

Rifkin, R. F., 2011. Assessing the efficacy of red ochre as a prehistoric hide tanning ingredient". Journal of African Archaeology 9 (2), 131-158.

Rifkin, R. F., 2012. Processing ochre in the Middle Stone Age: Testing the inference of prehistoric behaviours from actualistically derived experimental data. Journal of Anthropological Archaeology 31, 174-195.

Rifkin, R.F., Dayet, L., Queffelec, A., Summers, B,, Lategan, M,, D'Errico, F., 2015. Evaluating the Photoprotective Effects of Ochre on Human Skin by. In: Vivo SPF Assessment: Implications for Human Evolution, Adaptation and Dispersal. PLoS ONE 10(9): e0136090. https://doi.org/10.1371/journal. pone.0136090

Rodríguez Asencio, J.A., Barrera Logares, J.M., 2015. Grabadores y colgantes de los niveles solutrenses de la cueva de La Lluera I. En: Collado Giraldo, H., García Arranz, J.J. (Eds.), Symbols in the Landscape: Rock Art and its Context. XIX International Rock Art Conference IFRAO. Arkeos 37, 671-684.

Roebroeks, W., Sier, M. J., Kellberg, T., De Loecker, D., Parés, J. M., Arps, C. E. S., Müncher, M. J., 2012. Use of red ochre by early Neandertals, Proccedings of the Natural Academy of Sciences of America 109(6), 1889-1894.

Rifkin, R.F., 2015. Ethnographic and experimental perspectives on the efficacy of ochre as a mosquito repellent. South African Archaeological Bulletin 70, 64-75.

Roselló-Izquierdo, E., Jonsson, L., Arribas, J.L., Llorente-Rodríguez, L., Morales-Muñiz, A., 2017. The European Hake (Merluccius merluccius, L.): A deep-water fishery during Neolithic times?. 19th FRWG Meeting Fish and Fishing Communities. Understanding Ancient and Modern Fisheries through Archaeological Fish Remains. Cerdeña.

Roselló-Izquierdo, E., Jonsson, L., Arribas, J.L., Llorente-Rodríguez, L., Morales-Muñiz, A., 2018. La merluza europea (Merluccius merluccius, L.) en la prehistoria vasca: implicaciones arqueozoológicas y paleoambientales. En: Paleoambiente y recursos Bióticos del Pleistoceno Superior Cantábrico. Estado de la cuestión a la luz de nuevas investigaciones (libro de abstract), 51-52. Universidad del País Vasco-Euskal Herriko Unibertsitatea.
Rosso, D., 2017a. Caracterización físico-química y análisis tecnológico de los pigmentos del Middle Stone Age de la Cueva de Porc-Epic (Dire Dawa, Etiopía). Universidad de Barcelona. http://hdl.handle.net/2445/123521.

Rosso, D., 2017b. Aproximación etnoarqueológica al uso de colorantes para el tratamiento del cabello el caso de los Hamar (Etiopía). Pyrenae 48(2-4), 123-149.

Rosso, D. E., D'Errico, F., Queffelec, A., 2017a. Patterns of change and continuity in ochre use during the late Middle Stone Age of the Horn of Africa: The Porc-Epic Cave record. PLoS ONE 12 (5): e0177298. https://doi.org/10.1371/journal. pone.0177298

Salomon, H., 2009. Les matières colorantes au début du Paléolithique supérieur: sources, transformations et fonctions. PhD diss., Université de Bordeaux 1. Bordeaux.

Salomon, H., Vignaud, C., Coquinot, Y., Beck, L., Stringer, C., Strivay, D., D'Errico, F., 2012. Selection and heating of colouring materials in the Mousterian level of Es-Skhul (c. 10000 years BF, Mount Carmel, Israel). Archaeometry 54(4), 698-722.

Salomon, H., Vignaud, C., Lahlil, S., Menguy, N., 2015. Solutrean and Magdalenian ferruginous rocks heat-treatment: accidental and/or deliberate action?". Journal of Archaeological Science 55, 100-112. http://dx.doi.org/10.1016/j. jas.2014.12.024

San Juan, C., 1983. Un grabado inédito sobre un disco de ocre de la cueva de la Chora (Cantabria). Ars Praehistorica 2, 177-180.

Seva, R., Biete, C., Landete, M. D., 2015. Analysis of the red ochre of the El Miron burial (Ramales de la Victoria, Cantabria, Spain). Journal of Archaeological Science, 84-98. http://dx.doi. org/10.1016/j.jas.2015.03.033

Seva Román, R., Landete Ruiz, M. D., Juan-Juan, J., Biete Bañón, C., Straus, L.G., González Morales, M.R., 2019. Sources of the ochres associated with the Lower Magdalenian "Red Lady" human burial and rock art. In: El Mirón Cave (Cantabria, Spain). Journal of Archaeological Science: Report 23, 265-280. https://doi.org/10.1016/j.jasrep.2018.10.024

Sinddall, R., 2018. Mineral Pigments in Archaeology: Their Analysis and the Range of Available Materials. Minerals 8 (5), Article 201. doi:10.3390/min8050201 www.mdpi.com/journal/ minerals

Soressi, M., D'errico, F., 2007. Pigment, gravures, parures: les comportements symboliques controversés des Néandertaliens. In : Les Néandertaliens. Biologie et cultures, edited by Bernard Vandermeersch and Bruno Maureille, 297-309. Éditions du CTHS, Paris.

Straus, L.G., González Morales, M.R., Cuenca-Solana, D., 2015. The Magdalenian human burial of El Mirón Cave (Ramales de la Victoria, Cantabria, Spain): introduction, background, discovery and context. Journal of Archaeological Science 60, 1-9.

Utrilla, P., 1981. El Magdaleniense inferior y medio en la costa cantábrica. Centro de Investigación y Museo de Altamira. Monografías n. 4. Ministerio de Cultura.

Utrilla, P., 1982. El yacimiento de la cueva de Abauntz (Arraiz, Navarra). Trabajos de Arqueología Navarra 3, 203-345.

Velliky, E. C., Porr, M., Conard, N.J., 2018. Ochre and pigment use at Hohle Fels cave: Results of the first systematic review of ochre and ochrerelated artefacts from the Upper Palaeolithic in Germany. PLoS ONE 13(12): e0209874. https:// doi. org/10.1371/journal. pone.0209874. 
Velo, J., 1984. Ochre as Medicine: A Suggestion for the Interpretation of the Archaeological Record. Current Anthropology 25, 674 .

Wadley, L., 2005. Putting ochre to the test: replication studies of adhesivesthat may have been used for hafting toolsin the Middle Stone Age. Journal of Human Evolution 49, 587-601.

Wadley, L., 2010. Compound-Adhesive Manufacture as a Behavioral Proxy for Complex Cognition in the Middle Stone Age. Current Anthropology 51, Supplement S111-S119.

Watts, I., 2002. Ochre in the Middle Stone Age of southern Africa: ritualized display or hide preservative?. South African Archaeological Bulletin 57(175), 1-14.

Watts, I., 2009. Red ochre, body painting, and language: interpreting the Blombos ochre. In: Botha, R., Knight, C. (Eds.), The Cradle of Language, 62-92. Oxford University Press.

Watts, I., 2010. The pigments from Pinnacle Point Cave 13B, Western Cape, South Africa. Journal of Human Evolution 59, 392-411.

Zilhão, J., Angelucci, D. E., Badal, E., D’ Errico, F., Daniel, F., Dayet, L., Douka, K., Higham, T. F. G., Martínez, M. J., Montes, R., Murcia, S., Pérez, C., Roldán, C., Vanhaeren, M., Villaverde, V., Wood, R., Zapata, J., 2010. Simbolic use of marine shells and mineral pigments by iberian neandertals, Procedings of the National Academy of Sciences of America 107(3), 1023-1028. 